\title{
Vibrio vulnificus induces the death of a major bacterial species in the mouse gut via cyclo-Phe-Pro
}

\author{
Jeong-A Kim ${ }^{\dagger}$ Bo-Ram Jang ${ }^{\dagger}$, Yu-Ra Kim, You-Chul Jung, Kun-Soo Kim and Kyu-Ho Lee (D)
}

\begin{abstract}
Background: A foodborne pathogen, Vibrio vulnificus, encounters normal microflora inhabiting the gut environments prior to causing fatal septicemia or gastroenteritis and should overcome the barriers derived from the gut commensals for successful infection. Its interactions with gut commensals during the infection process, however, have not yet been understood. In the present study, the effect of $V$. vulnificus on the community structures of gut microbiota in mice was examined.

Results: Analyses of microbiota in the fecal samples of mice that died due to $V$. vulnificus infection revealed the decreased abundance of bacteria belonged to Bacteroidetes, notably, the species Bacteroides vulgatus. In vitro coculturing of the two bacterial species resulted in the decreased survival of B. vulgatus. The antagonistic effect of $V$. vulnificus against $B$. vulgatus was found to be mediated by cyclo-Phe-Pro (cFP), one of the major compounds secreted by V. vulnificus. cFP-treated B. vulgatus showed collapsed cellular morphology with an undulated cell surface, enlarged periplasmic space, and lysed membranes, suggesting the occurrence of membrane disruption. The degree of membrane disruption caused by cFP was dependent upon the cellular levels of ObgE in B. vulgatus. Recombinant ObgE exhibited a high affinity to CFP at a 1:1 ratio. When mice were orally injected with cFP, their feces contained significantly reduced B. vulgatus levels, and their susceptibility to $V$. vulnificus infection was considerably increased.
\end{abstract}

Conclusions: This study demonstrates that $V$. vulnificus-derived cFP modulates the abundance of the predominant species among gut commensals, which made $V$. vulnificus increase its pathogenicity in the hosts.

Keywords: Vibrio vulnificus, Cyclo-Phe-Pro, Gut microbiota, Bacteroides vulgatus, Membrane disruption, ObgE

\section{Introduction}

During the infection processes of foodborne pathogens, they encounter numerous stresses through the gastrointestinal (GI) tract of the host. While surviving the fluctuating conditions of $\mathrm{pH}$, oxygen, osmolarity, and nutrients [1,2], they should also overcome the barriers of host epithelial structures and the antimicrobials produced by the host's immune system [3, 4]. Therefore,

\footnotetext{
* Correspondence: kyuholee@sogang.ac.kr

${ }^{\dagger}$ Jeong-A Kim and Bo-Ram Jang contributed equally to this work. Department of Life Science, Sogang University, 35 Baekbeom-Ro, Mapo-Gu, Seoul, South Korea
}

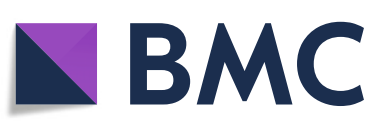

(c) The Author(s). 2021 Open Access This article is licensed under a Creative Commons Attribution 4.0 International License, which permits use, sharing, adaptation, distribution and reproduction in any medium or format, as long as you give appropriate credit to the original author(s) and the source, provide a link to the Creative Commons licence, and indicate if changes were made. The images or other third party material in this article are included in the article's Creative Commons licence, unless indicated otherwise in a credit line to the material. If material is not included in the article's Creative Commons licence and your intended use is not permitted by statutory regulation or exceeds the permitted use, you will need to obtain permission directly from the copyright holder. To view a copy of this licence, visit http://creativecommons.org/licenses/by/4.0/ The Creative Commons Public Domain Dedication waiver (http://creativecommons.org/publicdomain/zero/1.0/) applies to the data made available in this article, unless otherwise stated in a credit line to the data.

successful infection requires the pathogens to perform cellular motility motivated by chemotactic sensing, penetration of the intestinal mucus layers, adherence to the epithelial surfaces, and colonization with production and/or secretion of virulence factors at the infection sites $[5,6]$. In the case of Vibrio vulnificus, an opportunistic foodborne pathogen responsible for deaths worldwide due to seafood-associated septicemia [7], there have been numerous reports regarding its diverse virulence factors. In addition to well-known lipopolysaccharide and capsular polysaccharide, the membrane-bound and secreted proteins, including the immunogenic 
lipoprotein A (IlpA), hemolysin/cytolysin (VvhA), metalloprotease $\mathrm{M}$ (VvpM), phospholipase A2 (PlpA), and multifunctional-autoprocessing repeats-in-toxin (MARTX) show diverse activities to cause immunogenicity, cytotoxicity, and cell death via necrosis or apoptosis $[8,9]$. Production of these virulence factors is strictly regulated by sensing the extracellular signals derived from hosts or bacteria to express them in appropriate conditions. Iron ions, an autoinducer (AI-2), and a cyclic dipeptide (cyclo-Phe-Pro [cFP]) have been listed as the main signal molecules involved in these regulations in $V$. vulnificus.

Most studies of $V$. vulnificus pathogenicity have focused on the bacterial effects on model animals at the levels of cells, tissues, or organs. Mammalian intestinal tracts are inhabited by an enormous amount of normal microflora made up of several hundred to a thousand species of bacteria, which primarily belong to the phyla Bacteroidetes, Firmicutes, Actinobacteria, and Proteobacteria [10, 11]. Interactions between pathogens and gut commensals have been reported in diverse pathogens in model systems. The antagonistic effects of gut commensals on entering pathogens are achieved via the restriction of resources available to pathogens, the competitive exclusion of pathogens from mucosal colonization, the inhibitory effects of antimicrobial compounds or appendages of the commensals, and the stimulation of host defense systems [12-16]. Therefore, the host animals, of which gut microbiomes experienced a change in their composition or abundance, showed altered susceptibility to foodborne pathogens. Increased pathogenicity in these host animals has been experimentally proven in infections by Salmonella enterica Typhimurium, Listeria monocytogenes, $V$. cholerae, and a pathogenic Escherichia coli [17-20]. Furthermore, some pathogens have shown the ability to affect gut microbiota by direct killing with the type VI secretion systems or bacteriocins $[21,22]$.

The results of these previous studies lead us to speculate the existence of a similar situation where foodborne $V$. vulnificus encounters the normal microflora in the guts. Therefore, this pathogen should interact with them to overcome the potential defense mechanisms directly or indirectly derived from the gut microbiota, while interacting with the hosts via timely produced virulence factors. In the present study, we observed dramatic changes in the gut microbiomes of mice upon infection by $V$. vulnificus, in which the levels of one of the representative gut commensals, Bacteroides vulgatus, were considerably decreased. The molecular characteristics in the decreased survival of $B$. vulgatus by $V$. vulnificus were delineated by demonstrating the specific interaction of a signal molecule, cFP of $V$. vulnificus with a putative GTPase protein in B. vulgatus.

\section{Results}

Reduced levels of $B$. vulgatus in the fecal microbiota of the $V$. vulnificus-infected mice

Fecal samples were collected from mice, which had been subjected to gavage with $V$. vulnificus and died within 20 $h$ post-infection. Two independent sets of infection experiments were performed, and a total of 5 fecal samples were retrieved (three and two animals died in experiments 1 and 2, respectively). As a negative control, fecal samples from healthy mice treated with $V$. vulnificusfree PBS were also collected at each experimental set (two animals in each set). Analysis of $16 \mathrm{~S}$ rDNA sequences amplified from the prokaryotic cells of the domain Bacteria in fecal samples showed that Bacteroidetes and Firmicutes were the major phyla occupying approximately $53 \%$ and $40 \%$ of total fecal microbiomes in the control mice, respectively (Fig. 1A). However, altered compositions of the two phyla were found in the $V$. vulnificus-fed mice: Although these two phyla were still the major phyla, Bacteroidetes and Firmicutes occupied approximately $33 \%$ and $61 \%$ of total fecal microbiomes, respectively (Fig. 1A). A principal coordinate analysis (PCoA) showed that the microbial compositions in most fecal samples of the $V$. vulnificusfed mice were distinct from those of the control mice (permutational multivariate analysis of variance [PERM ANOVA], $P=0.024$ ) (Fig. 1B).

When the percentages of Bacteroidetes in the fecal samples were analyzed, their median values were $53.1 \%$ and $32.1 \%$ in the control mice and $V$. vulnificus-fed mice, respectively (Fig. 1C), and the difference between the two groups was significant (Mann-Whitney $U$ test, $P=0.014$ ). Among the bacteria belonging to Bacteroidetes, $B$. vulgatus, which has been recently reclassified as Phocaeicola vulgatus [23], was shown to be the most abundant species in mouse feces in both sets of experiments (Additional file: Table S1). The predominant abundance of B. vulgatus was consistent with the data previously reported [20]. Median values of the percentages of $B$. vulgatus in control mice and $V$. vulnificus-fed mice were $41.6 \%$ and $29.0 \%$, respectively (Fig. 1D). Reduced levels of B. vulgatus were observed in all of the $V$. vulnificus-fed mice in each set of experiments (Mann-Whitney $U$ test, $P=0.050$ ): $52.5 \% \pm$ $9.5 \%$ in the control vs. $33.2 \% \pm 6.5 \%$ in the infected mice in experiment 1 ; and $36.4 \% \pm 1.5 \%$ in the control vs. $27.8 \% \pm 1.8 \%$ in the infected mice in experiment 2 (Additional file: Table S1). In addition to B. vulgatus, another bacterial species belonged to Bacteroidetes such as Parabacteroides goldsteinii also decreased in the $V$. vulnificusfed mice (Additional file: Table S1). In contrast, some Lactobacillus species, which were the main bacteria belonging to Firmicutes in the mouse guts, did not show a decrease in their levels in $V$. vulnificus-fed fecal samples, but these increased in some animals. 


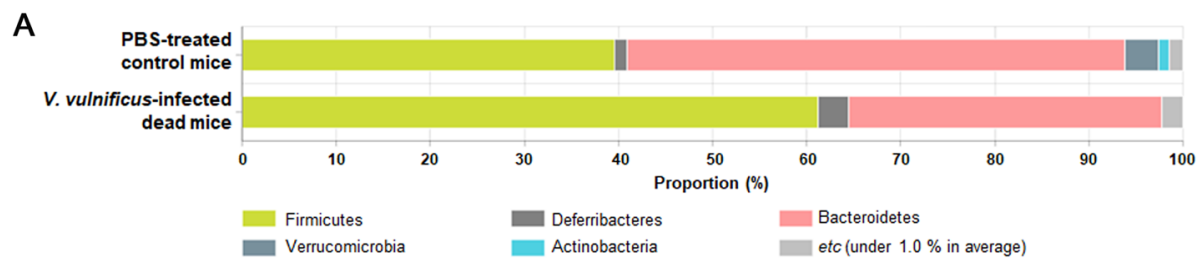

B

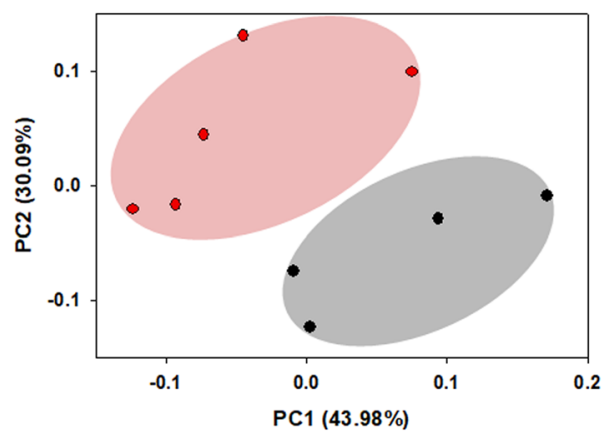

- PBS-treated mice

V. vulnificus-infected dead mice

C

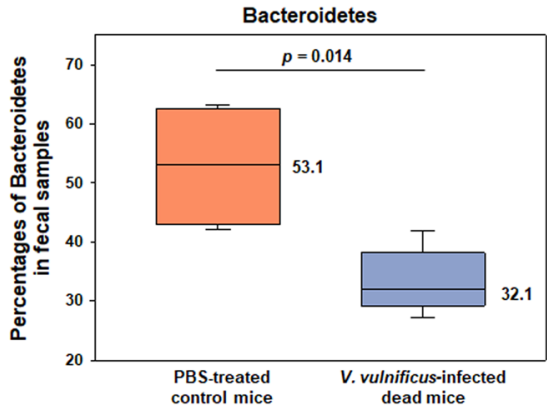

D

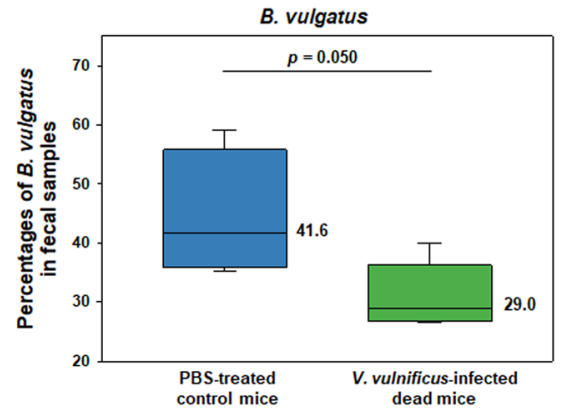

Fig. 1 Microbiome analyses of fecal samples collected from $V$. vulnificus-infected mice. A Abundance of the bacterial phyla in fecal samples of $V$. vulnificus-infected mice. After the oral infection of mice with $V$. vulnificus, their fecal samples were collected from the cages individually containing dead mice $(n=5)$. Mice orally injected with $V$. vulnificus-free PBS were used as a negative control $(n=4)$. Each fecal sample was subjected to $16 \mathrm{~S}$ rDNA sequencing to analyze the microbial community as described in "Methods." The bacterial phyla are differently colored as indicated below the bar chart. All phyla comprising less than $1.0 \%$ of the total abundance (whether classified or not) were combined into the "etc" category. B Principal coordinate analysis (PCOA) clustering of the bacterial communities in the mouse fecal samples. Community structures of microbiome derived from sequencing analysis of $16 \mathrm{~S}$ rDNAs in the fecal samples of $V$. vulnificus-infected dead mice and PBS-treated control mice were subjected to PCoA based on Jensen-Shannon distance method. A resultant plot was generated across the samples, in which the black and red circles represent the species composition of PBS-treated mice and $V$. vulnificus-infected dead mice, respectively (PERMANOVA, $P=0.024)$. C and $\mathbf{D}$ Comparison of relative abundance of Bacteroidetes and Bacteroides vulgatus in the mouse fecal samples. The percentages of $165 \mathrm{SDNA}$ copies belonged to the phylum Bacteroidetes $(\mathbf{C})$ and the species of $B$. vulgatus (D) in the fecal samples of $V$. vulnificus-infected dead mice were compared with those of PBS-treated control mice. Their distribution was plotted with each median value, and statistical significance between two groups was determined using the Mann-Whitney $U$ test

\section{Decreased viability of $B$. vulgatus in the presence of $V$. vulnificus}

To examine whether the decrease in B. vulgatus levels in the $V$. vulnificus-fed mice was caused by an interaction between these two species of bacteria, a strain of $B$. vulgatus (MGM001; Additional file: Table S2) was isolated as described in "Methods." In addition to MGM001, two strains of B. vulgatus were purchased from the American Type Culture Collection (ATCC) and Deutsche Sammlung von Mikroorganismen und Zellkulturen (DSMZ). Three strains of B. vulgatus were anaerobically incubated in the M9minimal medium with $V$. vulnificus. After $6 \mathrm{~h}$ of coincubation of $B$. vulgatus with $V$. vulnificus at ratios of 1:1, 1:2, and 1:5, serially diluted cocultures were spot-inoculated on RCM agar plates and incubated in an anaerobic chamber for the growth of B. vulgatus (Fig. 2A). The same aliquots were spot-inoculated on LBS agar plates for $V$. vulnificus growth (Fig. 2B). For comparisons of the viable cells of each species in the monocultures, these were also prepared to contain either B. vulgatus only (designated as 1:0) or $V$. 


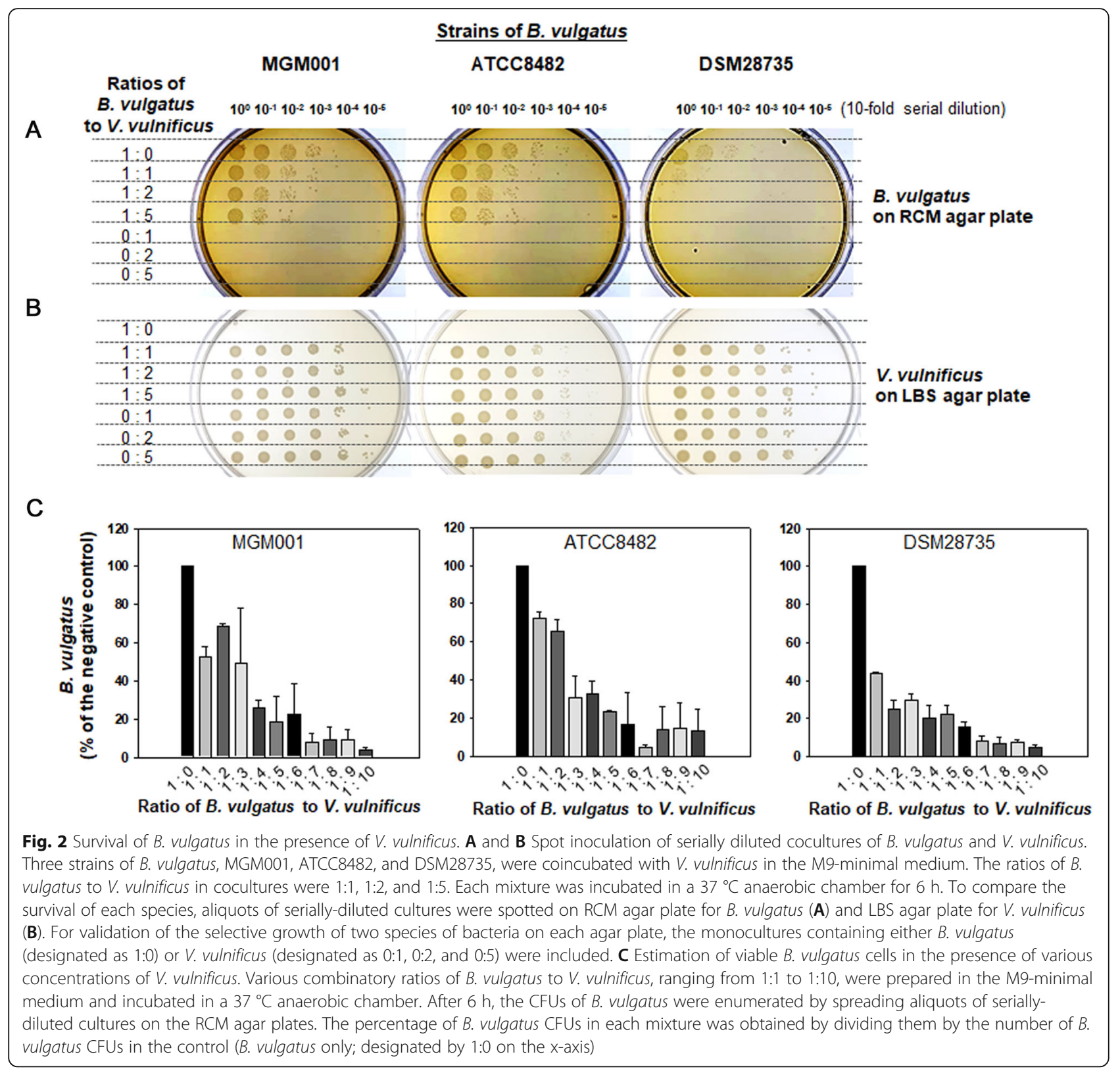

vulnificus only (designated as 0:1, 0:2, and 0:5). The viability of all $B$. vulgatus strains tested in this study decreased in the presence of $V$. vulnificus, of which reduction appeared to be dependent on the abundance of $V$. vulnificus in cocultures. On the other hand, the viability of $V$. vulnificus was not affected by $B$. vulgatus.

To examine the dose-dependent reduction in $B$. vulgatus viability, the same amount of $B$. vulgatus was incubated under the conditions of various amounts of $V$. vulnificus, at ratios of $B$. vulgatus to $V$. vulnificus ranging from 1:1 to $1: 10$ (Fig. 2C). After $6 \mathrm{~h}$, viable members of $B$. vulgatus were enumerated by spreading aliquots of serially-diluted cultures on the RCM agar plates. The results showed that the effect of $V$. vulnificus on $B$. vulgatus viability was antagonistic in a dose-dependent manner. The responses of the three strains of $B$. vulgatus to $V$. vulnificus were evaluated by comparing the ratios of $B$. vulgatus to $V$. vulnificus, which resulted in $50 \%$ reduction of viable cells of $B$. vulgatus: Calculated ratios of MGM001, ATCC8482, and DSM28735 to V. vulnificus were 1:2.0, 1:2.1, and 1:1.0, respectively. The strain MGM001, which has been isolated in this study, was used for the subsequent investigations.

\section{Identification of an antagonistic compound in the $V$. vulnificus-spent medium}

To examine how $V$. vulnificus affected the viability of $B$. vulgatus, both bacteria were spotted on a RCMS (salt- 
enriched RCM) agar plate, on which two bacterial colonies grew and were in contact with each other. Resultant interaction between the two colonies showed the presence of a growth inhibition zone of the $B$. vulgatus colony confronting the $V$. vulnificus colony (Fig. 3A). This suggested that the inhibition of $B$. vulgatus growth may have been mediated by a direct interaction with $V$. vulnificus cells and/or an indirect interaction via secreted compounds from $V$. vulnificus. To test these hypotheses, the involvement of the type VI secretion system (T6SS) of $V$. vulnificus in limiting the growth of $B$. vulgatus via direct contact, was examined. A mutant ( $\triangle i c m F)$ deficient in one of the T6SS components of $V$. vulnificus, i.e., IcmF (the intracellular multiplication factor F [25];), was constructed and mixed with B. vulgatus cells. However, it showed the same degrees of $B$. vulgatus survival shown by the wild-type $V$. vulnificus
(Additional file: Figure S1A), which suggested that $B$. vulgatus death was not caused by direct cell-to-cell interaction via T6SS of $V$. vulnificus.

Next, the cell-free supernatant derived from the LBS broth grown by $V$. vulnificus to the stationary phase (spent medium, SM) was prepared and various volumes of the filter-sterilized SM were added to B. vulgatus (Fig. 3B). Compared to the control, $0 \%$ of SM (the fresh LBS medium only), the addition of SM resulted in a decrease in B. vulgatus viability in a dose-dependent manner. This suggested the possible role of $V$. vulnificus-originating and $V$. vulnificus-secreted substance(s) in the death of $B$. vulgatus. To screen the active components in SM, the major metabolites produced by $V$. vulnificus under anaerobic conditions, including pyruvate, formate, lactate, and acetate [26], were added to a suspension of $B$. vulgatus cells (Additional file: Figure S1B). None were shown
A

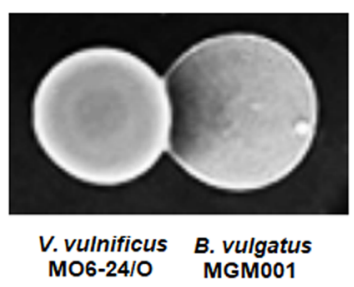

B

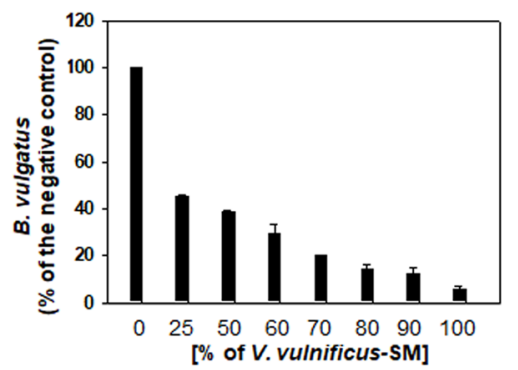

C

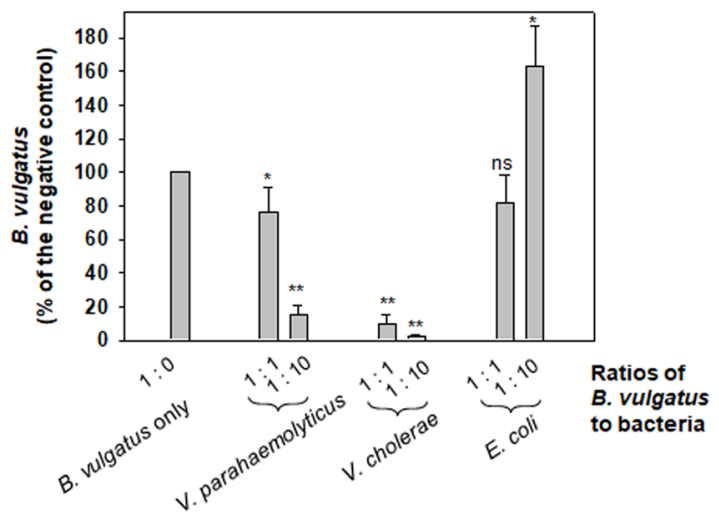

D

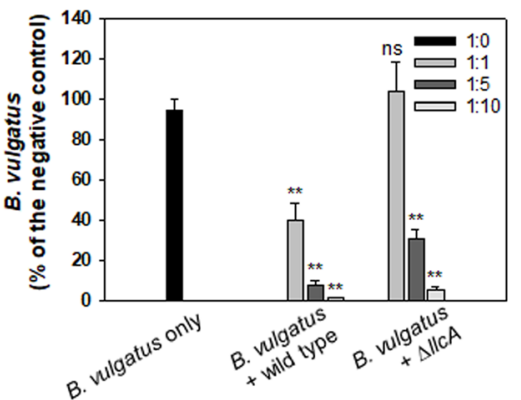

Fig. 3 Effects of various components in the supernatants of $V$. vulnificus-cultures on the survival of B. vulgatus. A Interaction between colonies of $V$. vulnificus and $B$. vulgatus. The resuspensions of the freshly grown cells of $V$. vulnificus and $B$. vulgatus were spotted in vicinity on a RCMS agar plate. After $24 \mathrm{~h}$ of anaerobic incubation at $37^{\circ} \mathrm{C}$, the growth pattern of each colony was observed. B Survival of $B$. vulgatus in the presence of cell-free supernatants of $V$. vulnificus. The cell-free supernatants (spent medium, SM) of $V$. vulnificus cultured in LBS for $18 \mathrm{~h}$ were prepared as described in the "Methods" section. Serially diluted SM with the fresh LBS broth was added to B. vulgatus. After $6 \mathrm{~h}$ anaerobic incubation at $37{ }^{\circ} \mathrm{C}$, B. vulgatus CFUs were enumerated as described in Fig. 2C. C Survival of B. vulgatus in the presence of Vibrio spp. and E. coli. B. vulgatus suspensions in M9-minimal medium were mixed with V. parahaemolyticus, V. cholerae, or E. coli at ratios of 1:1 and 1:10 (B. vulgatus to other bacteria), and incubated in a $37{ }^{\circ} \mathrm{C}$ anaerobic chamber for $6 \mathrm{~h}$. After $6 \mathrm{~h}$, the CFUs of B. vulgatus were enumerated as described in "Methods." The $P$-values for the comparison with the control (B. vulgatus only) are indicated (Student's $t$-test; ns, not significant; ${ }^{*} 0.001<P \leq 0.01$; ${ }^{* *} P \leq 0.001$ ). D Survival of $B$. vulgatus in the presence of a mutant $V$. vulnificus producing less CFP. An I/cA-defective $V$. vulnificus, which has been shown to produce significantly lowered amounts of CFP [24], was mixed with B. vulgatus at ratios of 1:1, 1:5, and 1:10 (B. vulgatus:V. vulnificus). B. vulgatus CFUs were enumerated as described in Fig. $2 \mathrm{C}$ 
to be effective in decreasing $B$. vulgatus survival to a concentration of at least $20 \mathrm{mM}$. In addition, the heated $\mathrm{SM}$, which had been treated at $95{ }^{\circ} \mathrm{C}$ for $5 \mathrm{~min}$ to denature its proteineous substances, was mixed with $B$. vulgatus (Additional file: Figure S1C). However, the heat-treated SM showed a similar effect to that of the original SM.

To circumvent the difficulty in finding the active compound(s), B. vulgatus was challenged by various bacterial species and its survival was examined (Fig. 3C). All the Vibrio species tested in this study showed antagonistic effects on B. vulgatus. Among them, $V$. cholerae was the most effective in decreasing the survival of $B$. vulgatus, since the incubations containing bacterial cells composed of a 1:1 ratio showed similar levels to those shown by the incubations containing 10 times more $V$. parahaemolyticus. In contrast, E. coli strain S17-1 spir did not exhibit this effect but instead slightly increased the B. vulgatus levels in the 1:10 incubation. Three Vibrio species tested in this study have been shown to produce a cyclic dipeptide, cFP, in their SM, and the concentration of cFP in the $V$. vulnificus SM has been estimated to be up to $0.9 \mathrm{mM}$ [27]. In addition, the incubation of $B$. vulgatus with a mutant $V$. vulnificus $(\Delta l l c A)$, of which production of cFP was estimated to be less than $\sim 30 \%$ of the wild type [24], resulted in lowered effectiveness in decreasing $B$. vulgatus survival, compared to that with the same amount of wild-type $V$. vulnificus (Fig. 3D). These results suggested that the death of $B$. vulgatus might be mediated by cFP secreted to SM.

To verify this, various concentrations of cFP, ranging from 0.125 to $1.0 \mathrm{mM}$, were added to the suspensions of three strains of $B$. vulgatus and incubated for $6 \mathrm{~h}$ (Fig. $4 \mathrm{~A}-\mathrm{C}$ ). The survival of all strains was significantly affected by cFP in a concentration-dependent manner. However, when a single amino acid, F or P, and the linear dipeptide F-P were added to $B$. vulgatus cells at the same concentrations used for cFP, they did not show any effect on B. vulgatus survival (Fig. 4D). Furthermore, other cyclic dipeptides, such as cyclo(Phe-Val) (cPV) and cyclo(Pro-Thr) (cPT), did not show any antagonistic result up to a concentration of $4 \mathrm{mM}$ (Fig. 4E). These
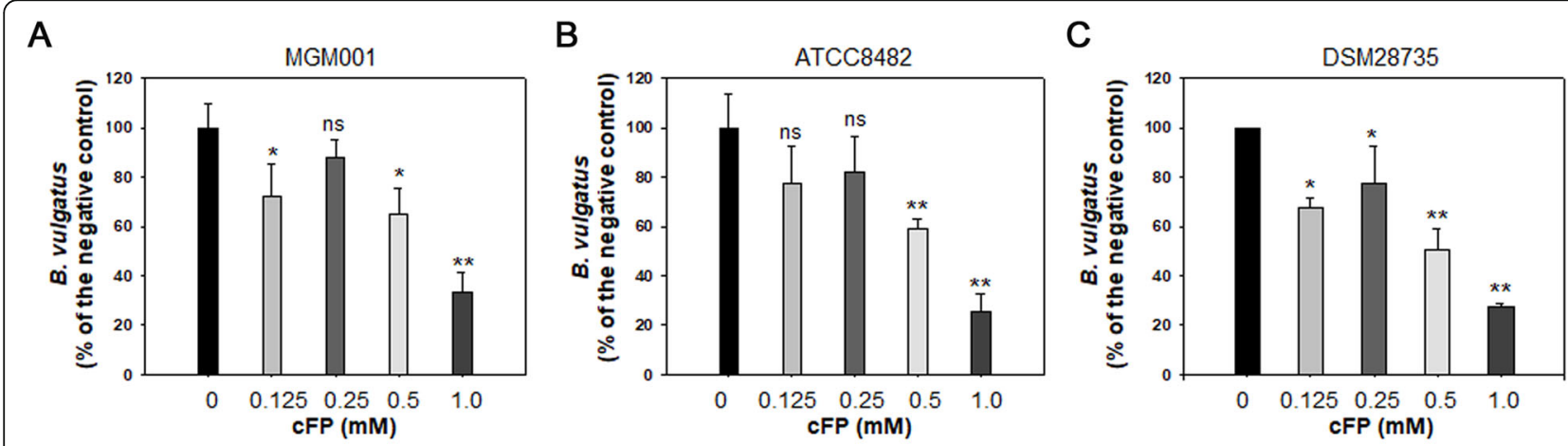

D

$\mathrm{E}$
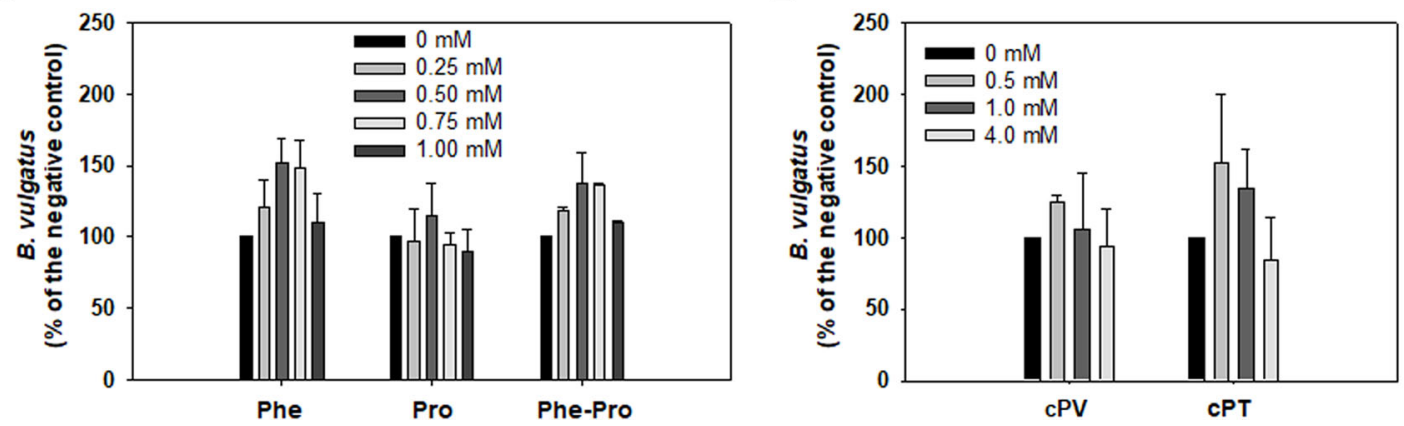

Fig. 4 Effects of exogenous addition of cyclic dipeptides on the survival of B. vulgatus. A, B, and $\mathbf{C}$ Effect of cyclo-Phe-Pro (cFP) on the survival of the strains of $B$. vulgatus. Various concentrations of CFP ranging from 0 to $1.0 \mathrm{mM}$ were added to the freshly grown cultures of three strains of $B$. vulgatus in M9 broth: MGM001 (A), ATCC8482 (B), and DSM28735 (C). At 6 h post-exposure to CFP, B. vulgatus CFUs were enumerated as described in Fig. 2C. The P-values for the comparison with the control $(0 \mathrm{mM} \mathrm{CFP})$ are indicated (Student's $t$-test; $n s$, not significant; ${ }^{*} 0.001<P \leq$ 0.01; $\left.{ }^{* *} P \leq 0.001\right)$. D Effects of Phe $(F)$, Pro $(P)$, and a dipeptide of Phe-Pro (F-P) on the survival of $B$. vulgatus. Various concentrations of $F$, P, and $F$ $P$ ranging from 0 to $1.0 \mathrm{mM}$ were added to the freshly grown culture of B. vulgatus MGM001. At 6 h post-exposure, B. vulgatus CFUs were enumerated as described in Fig. 2C. E Effects of other cyclic dipeptides on the survival of B. vulgatus. Various concentrations of cyclo-Phe-Val (cPV) and cyclo-Pro-Thr (CPT) ranging from 0 to $4.0 \mathrm{mM}$ were added to the freshly grown culture of $B$. vulgatus MGM001. At $6 \mathrm{~h}$ post-exposure, $B$. vulgatus CFUs were enumerated as described in Fig. $2 \mathrm{C}$ 
results suggested that the $V$. vulnificus-originated cFP determined the specificity of the interaction between $B$. vulgatus and $V$. vulnificus.

\section{Induction of $B$. vulgatus cell death by cFP}

To directly observe the effect of cFP on $B$. vulgatus cells, the strain MGM001 was treated for $6 \mathrm{~h}$ with various concentrations of cFP ranging from 0 to $4.0 \mathrm{mM}$, and then stained using a Live/Dead cell double staining kit (Sigma-Aldrich) (Fig. 5A). Through fluorescence microscopy, the number of red-stained dead cells were found to increase with cFP concentration, while the number of green-stained live cells gradually decreased (Fig. 5B).

The increased death of B. vulgatus observed via staining with fluorescence dyes was confirmed using electron microscopes. Scanning electron microscopy (SEM) of the MGM001 cells (Fig. 5C), which were treated with 4.0 $\mathrm{mM}$ cFP for $6 \mathrm{~h}$, showed the collapsed cellular morphology with undulated cell surfaces. In addition, transmission electron microscopy (TEM) of three B. vulgatus strains presented dramatic alteration in cellular morphology upon treatment with cFP, with enlarged periplasmic space, lyzed membranes, and partially ruptured cells (Fig. 5D-F). It indicated the occurrence of membrane disruption in the cFP-treated cells.

\section{Effects of cFP on Parabacteroides and Lactobacillus}

From an effort to obtain pure cultures of microorganisms from mouse guts, another bacterial species, $P$. goldsteinii belonging to Bacteroidetes and several Lactobacillus species belonging to Firmicutes have been isolated (mouse gut microorganism (MGM) isolates; Additional file: Table S2). For the addition of $V$. vulnificus cells $\left(2.0 \times 10^{8}\right.$ cells; Fig. $\left.6 \mathrm{~A}\right)$ or $\mathrm{cFP}(1$ and $4 \mathrm{mM}$; Fig. $6 \mathrm{~B})$ to the resuspensions of the isolated gut commensals, only $P$. goldsteinii experienced decreased survival, while the survival of Lactobacillus species (i.e., $L$. johnsonii, L. reuteri, L. murinus, and L. intestinalis) was not decreased. Observation of cFP-treated P. goldsteinii cells under TEM showed apparent membrane disruption (Fig. 6C), as shown in the cFP-treated B. vulgatus.

\section{cFP-induced cell death of $B$. vulgatus via membrane disruption}

To examine the changes in membrane integrity, a fluorescent dye, 3,3'-dipropylthiadicarbocyanine iodide (DiSC3(5)), was used to incorporate into bacterial membranes [28]. Then, the amount of DiSC3(5) released from bacterial cells was measured upon cell lysis by exposure to a membrane permeabilizing agent, such as Triton X-100. Total amounts of the membraneassociated DiSC3(5) were estimated by measuring the fluorescence released from the cells treated with $0.1 \%$ Triton X-100, for which almost all B. vulgatus cells were lysed. To determine the effective concentration of Triton $\mathrm{X}-100$ causing the lysis of $50 \%$ B. vulgatus cells $\left(\mathrm{EC}_{50}\right)$, various concentrations of Triton $\mathrm{X}-100$ were exposed to DiSC3(5)-associated B. vulgatus. By plotting the percentages of dyes normalized with the estimate of released $\operatorname{DiSC} 3(5)$ at $0.1 \%$ Triton X-100, as described in "Methods," $\mathrm{EC}_{50}$ was calculated to be approximately $0.002 \%$ (Fig. 7A). The released fluorescence upon exposure to $0.002 \%$ Triton $\mathrm{X}-100$ from B. vulgatus cells treated with $4 \mathrm{mM} \mathrm{cFP}$ (termed by $\Delta_{4} \mathrm{mM}$ cFP) and the control B. vulgatus cells (termed by $\Delta_{0} \mathrm{mM}$ cFP) was estimated (Fig. 7B). The values of $\Delta_{0} \mathrm{mM} \mathrm{cFP}$ and $\Delta_{4} \mathrm{mM}$ cFP were estimated at $605( \pm 64)$ and $727( \pm 80)$ RFUs, which was equivalent to $29 \%( \pm 2.3 \%)$ and $43 \%( \pm 3.7 \%)$ of the total fluorescence initially incorporated into the cells, respectively. This difference was significant with a $P$ value less than 0.008 (Student's $t$-test). These results evidencing the increased susceptibility of cFP-treated cells to Triton X-100 suggested that cFP caused the membranes of $B$. vulgatus to be permeable, thus easily disruptive.

To differentiate whether this increased susceptibility to a membrane permeabilizing stress was specifically mediated by cFP or caused by any dipeptide composed of hydrophobic amino acids, the same experiments were performed using $4 \mathrm{mM}$ of $\mathrm{FP}, \mathrm{cPT}$, and $\mathrm{CPV}$ (Additional file: Figure S2). B. vulgatus cells treated with FP, cPT, or cPV showed a slightly lowered basal RFU (averaged RFUs for 10 min before Triton X-100 treatment) compared to the control and much lower maximal RFU (averaged RFUs for 10 min after Triton X-100 treatment) than the cFPtreated cells. Upon the addition of $0.002 \%$ Triton X-100, $B$. vulgatus cells treated with these dipeptides produced $\Delta_{4 \mathrm{xmM}}$ dipeptide values $(562,572$, and 561 RFUs in treatment with $\mathrm{FP}, \mathrm{cPT}$, and $\mathrm{cPV}$, respectively) with similar ranges to that of the control cells (608 RFUs).

\section{Identification of a B. vulgatus factor involved in CFP- mediated membrane disruption}

Some factors, such as RecA, CidA, and ObgE, have been found to regulate the integrity of bacterial membranes under specific conditions [29-32]. The genomes of $B$. vulgatus have the open reading frames (ORFs) homologous to these genes, though their functions have not yet been studied. To screen the factor(s) involving the cFPmediated membrane disruption, the cellular abundance of $o b g E, \operatorname{cid} A$, and $r e c A$ transcripts and proteins were monitored in $B$. vulgatus cells incubated under the conditions in the absence or presence of cFP. Transcript levels of the $o b g E$, of which contents were normalized with the gap transcript levels in the same cells, were increased as the exposure time was extended (about threefold increase in the $4 \mathrm{~h}$ incubation compared to $0 \mathrm{~h}$ incubation), while those of $\operatorname{cid} A$ and $\operatorname{rec} A$ were not altered 


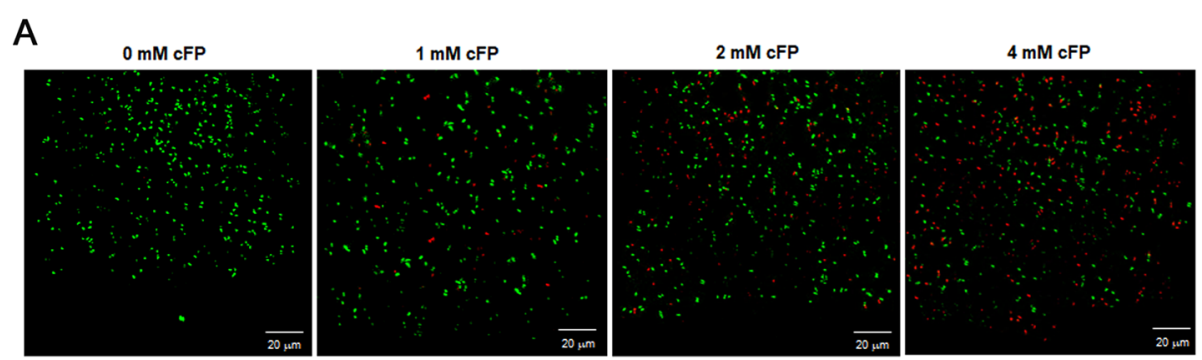

B

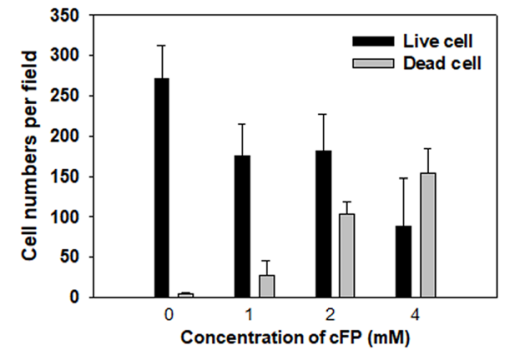

C
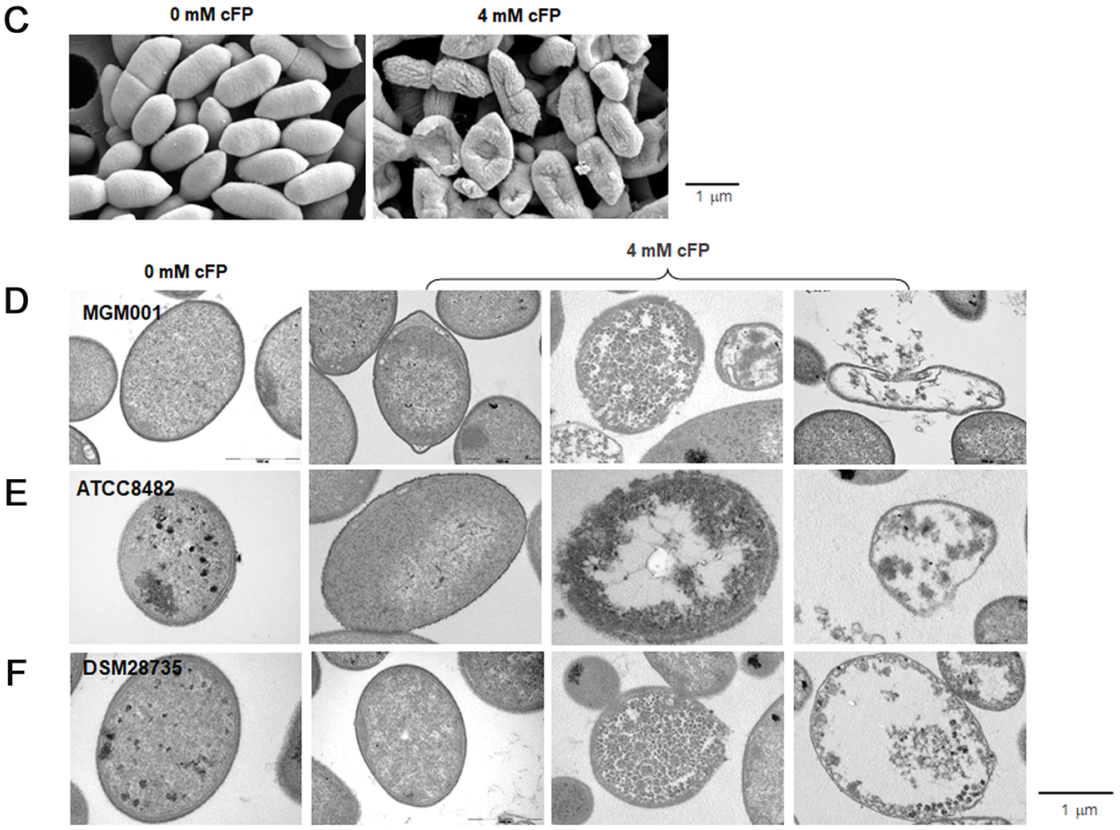

Fig. 5 Cell death of B. vulgatus in the presence of CFP. A and B Live/Dead staining of B. vulgatus cells. Cells of B. vulgatus MGM001 were treated for $6 \mathrm{~h}$ with various concentrations of CFP ranging from 0 to $4.0 \mathrm{mM}$, and then stained with the Live/Dead cell double staining kit (A). Live and dead cells were enumerated by counting the green- and red-stained cells in at least eight fields, respectively, and their averages and standard deviations were plotted against the exposed concentrations of CFP (B). C SEM of B. vulgatus cells. B. vulgatus MGM001 was treated with 4.0 mM cFP for $6 \mathrm{~h}$, then processed for SEM analysis as described in "Methods." The length of a horizontal bar represents $1 \mu \mathrm{m}$. D, E, and $\mathbf{F}$ TEM of $B$. vulgatus cells. Four millimolar of cFP was added to the freshly grown cultures of three B. vulgatus strains; MGM001 (B), ATCC8482 (C), and DSM28735 (D). At $6 \mathrm{~h}$ post-exposure to CFP, B. vulgatus cells were processed for TEM analysis as described in "Methods." For comparison, TEM images of the control cells ( $0 \mathrm{mM}$ cFP) were presented in the left panels. The length of a horizontal bar represents $1 \mu \mathrm{m}$

up to $4 \mathrm{~h}$ incubation period (Fig. 8A). Protein levels in cells were examined using specific polyclonal antibodies against recombinant ObgE and RecA of B. vulgatus (Fig. $8 \mathrm{~B})$. Due to no apparent induction of rCidA from the overexpression vector carrying the cidA gene, an experiment to compare the cellular CidA levels was not successful. In addition to the increase in the $o b g E$ transcript, the protein content of ObgE increased in the $B$. vulgatus cells exposed to cFP. These results lead us to speculate the possible involvement of ObgE in the observed membrane disruption in B. vulgatus exposed to cFP. 
A

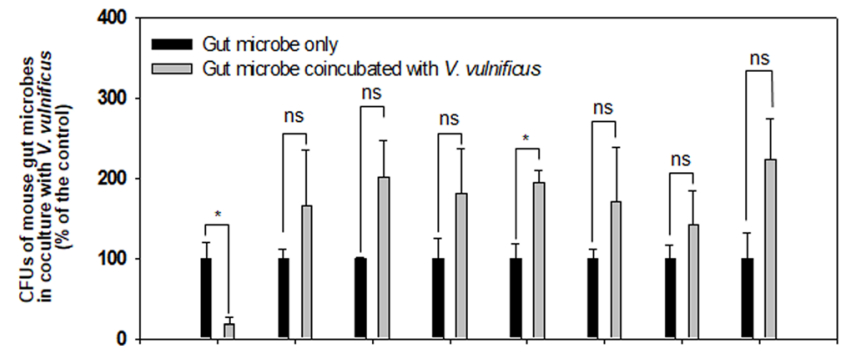

B
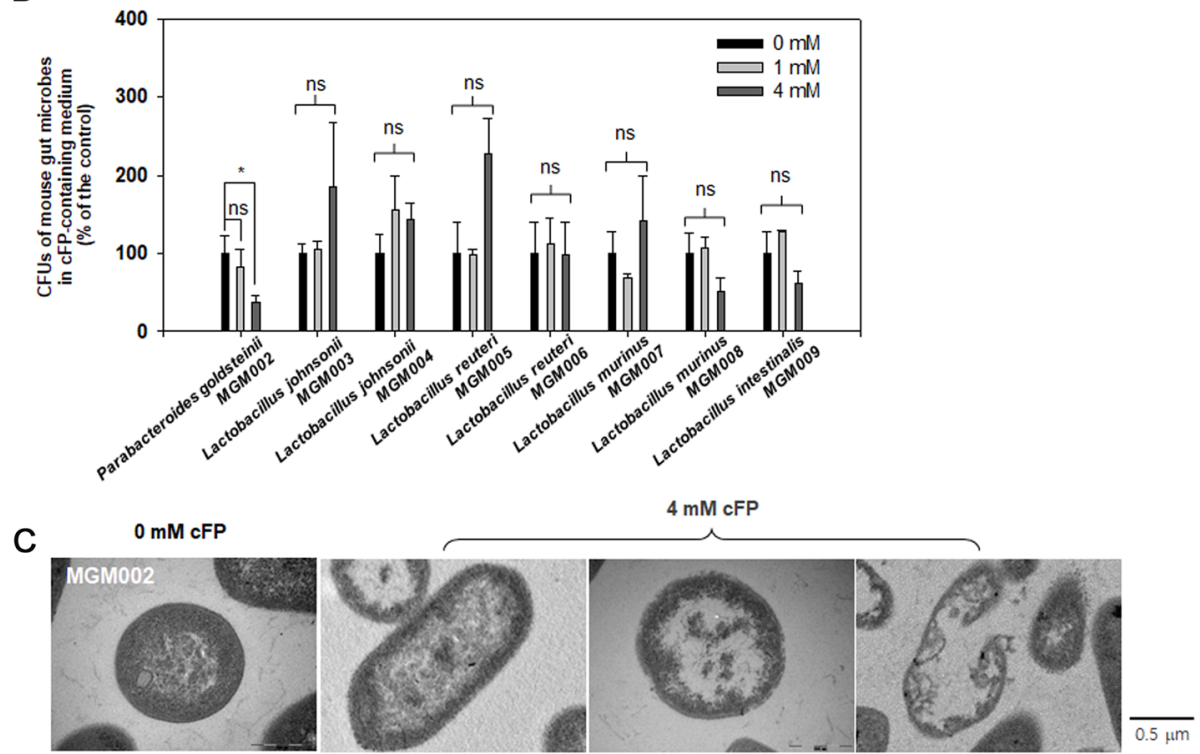

Fig. 6 Responses of various MGM isolates to $V$. vulnificus and CFP. $\mathbf{A}$ and $\mathbf{B}$ Effects of $V$. vulnificus cells and cFP on the survival of MGM strains. Various bacterial strains (MGM isolates listed in the Additional file: Table S2) were incubated under the conditions with $5.0 \times 10^{9}$ cells of $\mathrm{V}$. vulnificus (A) or supplemented with cFP at concentrations of 1 and $4 \mathrm{mM}$ (B). At $6 \mathrm{~h}$ of incubation, CFUs of the MGM strains were enumerated and presented with the percentage of each control (the same cultures but without treatment of $V$. vulnificus (A) or CFP (B)). The $P$-values for the comparison with the control (MGM only) are indicated (Student's $t$-test; ns, not significant; ${ }^{*} 0.001<P \leq 0.01$ ). C TEM of $P$. goldsteinii cells. Four millimolar CFP was treated to the freshly grown culture of P. goldsteinii MGM002. At $6 \mathrm{~h}$ post-exposure to CFP, cells were processed for TEM analysis as described in the "Methods." For comparison, a TEM image of no cFP-treated cells was presented in the left panel. The length of a horizontal bar represents $0.5 \mu \mathrm{m}$

To elucidate the specific interaction of ObgE with cFP, the isothermal titration calorimetry (ITC) experiments were performed using nucleotide-free rObgE, as described in "Methods." In total, $40 \mu \mathrm{M}$ of rObgE was titrated at $25{ }^{\circ} \mathrm{C}$ with a cFP stock solution of 400 $\mu \mathrm{M}$ (Fig. 8C). The equilibrium dissociation constant $\left(\mathrm{K}_{\mathrm{D}}\right)$ and binding stoichiometry $(N)$ for the interaction between $\mathrm{rObgE}$ and $\mathrm{cFP}$ were $1.8 \pm 0.35 \mu \mathrm{M}$ and 0.78 \pm 0.11 , respectively. In contrast, the titration of rObgE with $400 \mu \mathrm{M}$ of another cyclic dipeptide, $\mathrm{cPT}$ did not show any signature for the inter-molecular interaction.

Since the B. vulgatus ObgE specifically interacted with cFP and its cellular contents increased in cFP-treated cells, the role of ObgE in membrane disruption was examined. It has been previously reported that a trial of $o b g E$ gene deletion was not successful in many bacterial species [33]. Therefore, we have constructed a cell enabling to overexpress $\mathrm{ObgE}$ in response to the concentration of arabinose, instead to attempt to construct an obgE deletion mutant of $B$. vulgatus. Differential expression of ObgE was achieved using B. vulgatus MGM001 harboring the $o b g E_{\mathrm{Bv}}$ gene in a vector, $\mathrm{pBAD} / M y c$-His $\mathrm{B}$ (pBAD-obg $E_{\mathrm{Bv}}$ ), which was added with $L$-arabinose at concentrations ranging from 0 to $1.0 \%$. For quantitative analysis, each cell lysate was subjected to western blotting along with the known concentrations of $\mathrm{rObgE}$ (Fig. 8D). Cellular contents of ObgE were estimated by extrapolating the densitometric readings of the ObgE bands derived from cell lysates to the regression line derived from those of the known concentrations of rObgE (from 0.2 to $10 \mathrm{ng}$ ). The estimated cellular contents of ObgE were increased from 1.3 to $2.5 \mathrm{ng}$ ObgE per $\mu \mathrm{g}$ of cell lysate by carrying pBAD-obg $E_{\mathrm{Bv}}$, and those of $B$. vulgatus 
A

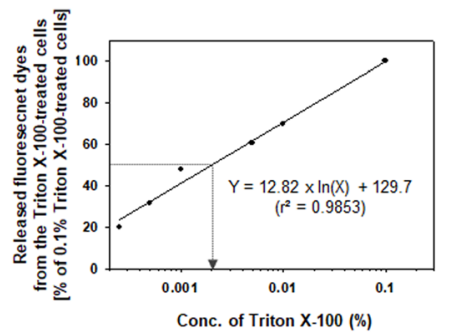

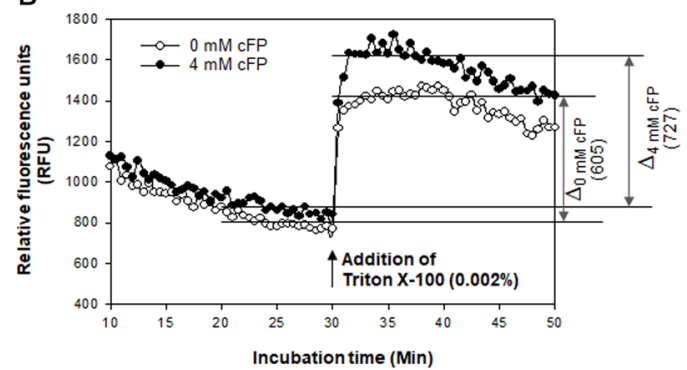

Fig. 7 Effect of CFP exposure on the membrane permeability of B. vulgatus. A Estimation of the $\mathrm{EC}_{50}$ of Triton X-100. Various concentrations of Triton X-100, ranging from $0.0003 \%$ to $0.1 \%$, were exposed to B. vulgatus MGM001 cells, which were incorporated with a membrane-associating fluorescent dye, DiSC3(5), as described in "Methods." Released fluorescence from the N\% Triton X-100-treated cells (termed $\Delta_{\text {N\%}}$ ) was obtained by subtracting the values of basal RFU (before treatment of N\% Triton X-100) from the maximal RFU (after treatment of N\% Triton X-100). These values were normalized with the estimates of DiSC3(5) released from the cells treated with $0.1 \%$ Triton $\mathrm{X}-100\left(\Delta_{0.1 \%}\right)$, at which almost all $B$. vulgatus cells were permeabilized. The ratios $\left(\left[\Delta_{\mathrm{N} \%} / \Delta_{0.1 \%}\right] \times 100\right)$ were plotted against the concentrations of Triton $X-100$. The arrow indicates the effective concentration ( $E C_{50}$ ) of Triton X-100 to release $50 \%$ of $\Delta_{0.1 \%}$. B Release of DiSC3(5) from cFP-treated B. vulgatus. A fluorescent dye, DiSC3(5), was used to examine the change in permeability of bacterial membrane. B. vulgatus cells, which had been exposed to $4 \mathrm{mM}$ cFP for 6 h, were mixed with $0.4 \mu \mathrm{M}$ DiSC3(5) for $1 \mathrm{~h}$. After unincorporated dyes were washed out, RFUs from DiSC3(5) associated with cells were measured. At $30 \mathrm{~min}$ (as indicated with a black vertical arrow), cells were treated with $0.002 \%$ Triton X-100, at which approximately $50 \%$ of the $B$. vulgatus cells were permeabilized (as shown in $\mathbf{A}$ ). The released fluorescence from the Triton X-100-treated cells was obtained by subtracting the values of basal RFUs (averaged RFUs for 10 min before treatment of $0.002 \%$ Triton X-100) from the maximal RFUs (averaged RFUs for 10 min after treatment of $0.002 \%$ Triton X-100). As a control, the cells untreated with CFP were followed by the same procedure and then $\Delta_{0} \mathrm{mM}$ cFP was compared with $\Delta_{4} \mathrm{mM}$ cFp. Each line was derived from the average values from the total six experiments

cells harboring pBAD- $o b g E_{\mathrm{Bv}}$ were further increased to 3.1, 4.9, and $9.3 \mathrm{ng}$ ObgE per $\mu \mathrm{g}$ of cell lysate if cells were incubated with $0.01 \%, 0.1 \%$, and $1.0 \%$ arabinose, respectively.

Then, we measured the membrane integrity in B. vulgatus cells having different levels of ObgE. The same cells prepared for the experiments shown in Fig. 8D were exposed to 4 or $0 \mathrm{mM} \mathrm{cFP}$ for $6 \mathrm{~h}$ and then mixed with 0.4 $\mu \mathrm{M} \operatorname{DiSC3}(5)$ for $60 \mathrm{~min}$. As described above, the values of released DiSC3(5) from 0.002\% Triton X-100-treated cells $\left(\Delta_{0.002}\right)$ were estimated and normalized with the total DiSC3(5) initially incorporated into cells $\left(\Delta_{0.1 \%}\right)$. The ratios $\left(\left[\Delta_{0.002 \%} / \Delta_{0.1 \%}\right] \times 100\right)$ shown in Fig. 8E revealed that the increase in cellular ObgE resulted in the increased release of the dyes upon treatment of $0.002 \%$ Triton X100 in an $\mathrm{ObgE}$ concentration-dependent manner (closed circles). Furthermore, the exogenous addition of $4 \mathrm{mM}$ cFP resulted in 1.7 2.0 times greater release of DiSC3(5) (open circles) than the each control cells without cFP treatment. These differences were significant with $P$ values less than 0.01 (Student's $t$-test).

\section{Alteration of mouse lethality by $V$. vulnificus via changes in $B$. vulgatus abundance in mouse guts}

The introduction of $V$. vulnificus resulted in the reduction of B. vulgatus levels in the fecal samples and this reduced composition was postulated to be mediated by cFP secreted by infecting $V$. vulnificus. Therefore, the effect of the exogenous addition of cFP on the abundance of $B$. vulgatus in mouse fecal samples was examined. The fecal samples were collected from 4-week-old female mice orally injected with cFP at a concentration of $110 \mu \mathrm{g}$ cFP per gram of mouse. The total DNA extracted from each fecal sample was subjected to q-PCR using a primer set specific to the $16 \mathrm{~S}$ rDNA of $B$. vulgatus (Bv-F and $\mathrm{Bv}-\mathrm{R}$ [34];) or the universal primer set for the eubacterial 16S rDNA (785F and 907R [35];). The relative abundance of $B$. vulgatus $16 \mathrm{~S}$ rDNA was normalized by the abundance of the total $16 \mathrm{~S}$ rDNAs derived from PCR using the universal primer set. The medians of estimated values of $2^{-[\mathrm{CT} \text { (B.vulgatus) }- \text { CT(Total }}$ Bacteria)] were $0.1369( \pm 0.0748)$ and $0.0619( \pm 0.0766)$ in the PBS-treated control $(n=20$ mice) and cFP-treated mice ( $n=20$ mice), respectively (Fig. 9A). Therefore, the levels of B. vulgatus decreased approximately 2.2-fold in mice injected with cFP $(P=0.006$, two-sided Student's $t$ test).

Next, we investigated whether the mice containing decreased levels of $B$. vulgatus showed a different susceptibility to infection by $V$. vulnificus. Mice were orally injected with cFP and they were infected at $12 \mathrm{~h}$ postinjection of cFP with various doses of $V$. vulnificus, ranging from $10^{4}$ to $10^{8}$ cells $(n=7$ mice per each treatment) (open symbol). The same experiments were performed using the control mice that had been injected with cFP-free DMSO cells $(n=7$ mice per each treatment) (closed symbol) (Fig. 9B). When infected with the highest dose of $V$. vulnificus (i.e., $10^{8}$ cells), mice under both conditions died equally and quickly within $24 \mathrm{~h}$. Similarly, the mice infected with the lowest dose of $V$. vulnificus (i.e., $10^{4}$ cells) showed similar patterns of 


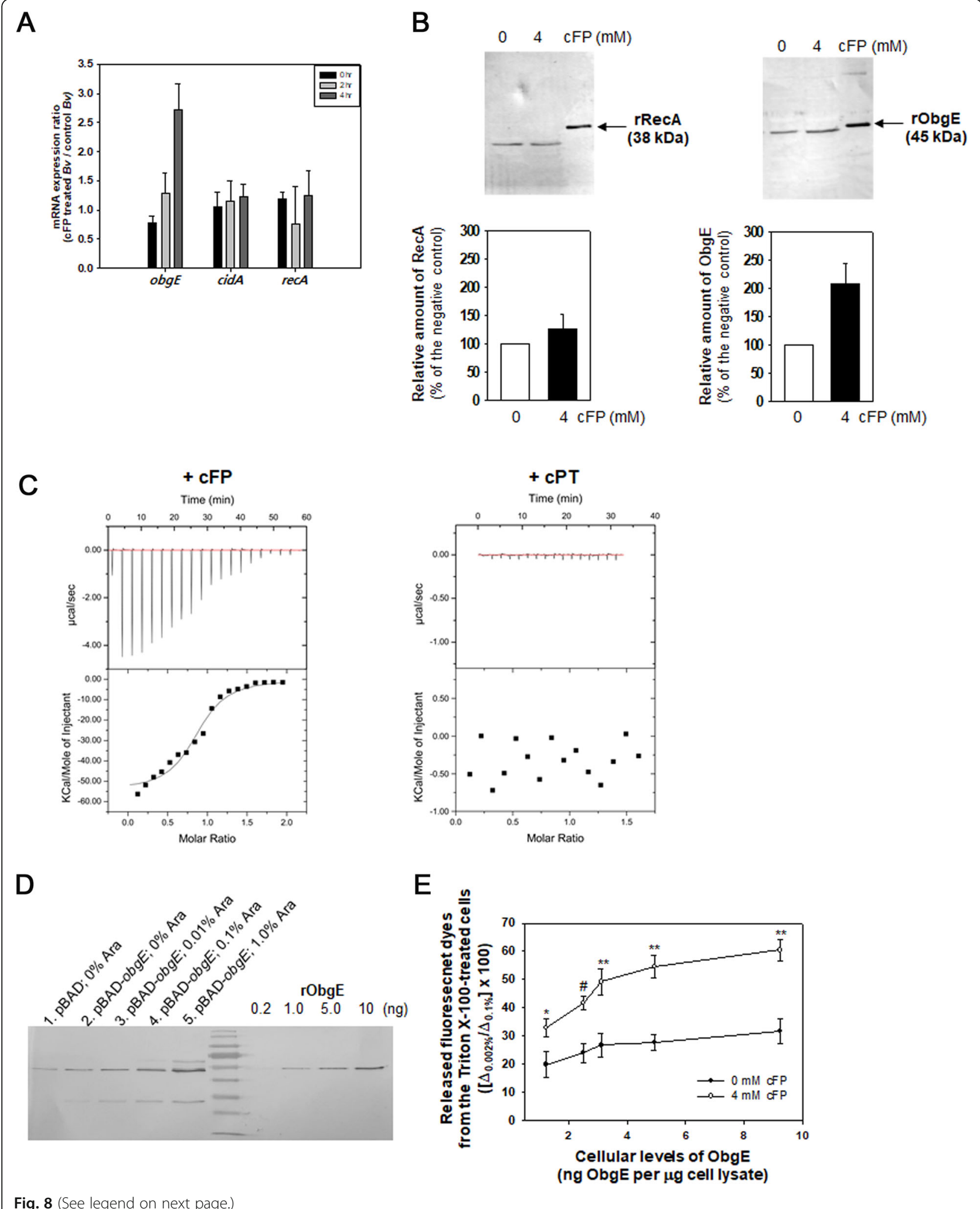


(See figure on previous page.)

Fig. 8 Role of ObgE in CFP-mediated change in the membrane permeability of B. vulgatus. A Transcript levels of obgE, recA, and cidA in cFPtreated B. vulgatus. The total RNAs were extracted from B. vulgatus cells treated with $4 \mathrm{mM}$ cFP for 0,2 , and $4 \mathrm{~h}$. Then, cDNAs were produced through the reverse transcriptase reaction and subjected to quantitative PCR using primer sets specific to obgE, recA, or cidA (Additional file: Table S3). The transcript contents of each gene were normalized with the gap transcript levels. The ratios of normalized contents in cFP-treated cells to those in the control cells were plotted. B Protein levels of ObgE and RecA in CFP-treated B. vulgatus. Fifteen micrograms of protein lysates of $B$. vulgatus, which had been exposed to 0 or $4 \mathrm{mM}$ cFP for $4 \mathrm{~h}$, were fractionated in SDS-PAGE and subjected to western blotting analysis using anti-ObgE and anti-RecA polyclonal antibodies. As a positive control, rRecA (38 kDa) and rObgE (45 kDa) were included in the blots.

Densitometric readings of the bands corresponding to each protein in the control and CFP-treated cells were plotted. C Specific binding of cFP to ObgE. Isothermal titration calorimetry (ITC) experiments were performed by titrating the recombinant ObgE (40 $\mu \mathrm{M})$ with $400 \mu \mathrm{M} \mathrm{CFP}$ at $25^{\circ} \mathrm{C}$ As a control, rObgE was titrated with $400 \mu \mathrm{M}$ CPT under the same condition for ITC. D Differential expression of ObgE in B. vulgatus cells. Freshly grown $B$. vulgatus carrying the vector plasmid ( $\mathrm{pBAD} / \mathrm{Myc}$-His $B$ ) or $\mathrm{pBAD}-\mathrm{obg} E_{\mathrm{Bv}}$ was added with various concentrations of $L$-arabinose ranging from $0 \%$ to $1.0 \%$ to differentially induce obgE expression. Upon $1 \mathrm{~h}$ induction, bacterial lysates $(2 \mu \mathrm{g})$ were subjected to western blotting along with the known concentrations (from 0.2 to $10 \mathrm{ng}$ ) of rObgE to estimate the cellular contents of ObgE. E Effect of the cellular levels of ObgE on membrane permeability. The same cells prepared in Fig. 8D were exposed to 4 or $0 \mathrm{mM} \mathrm{cFP}$ for $6 \mathrm{~h}$ then mixed with $0.4 \mu \mathrm{M}$ DiSC3(5). As described in Fig. 7, the values of released DiSC3(5) from $0.002 \%\left(\Delta_{0.002 \%}\right)$ and $0.1 \%$ Triton X-100-treated cells $\left(\Delta_{0.1 \%}\right)$ were estimated. The ratios $\left(\left[\Delta_{0.002 \%} / \Delta_{0.1 \%}\right] \times 100\right)$ were plotted against the cellular contents of ObgE. shown in Fig. 8D. P-values for the comparison of $4 \mathrm{mM} c$ FP-treatment with no CFP-treatment are indicated (Student's $t$-test; ns, not significant; ${ }^{*} 0.001<P \leq 0.01$; ${ }^{* *} P \leq 0.001$; ${ }^{*}$ no $p$ value determined)

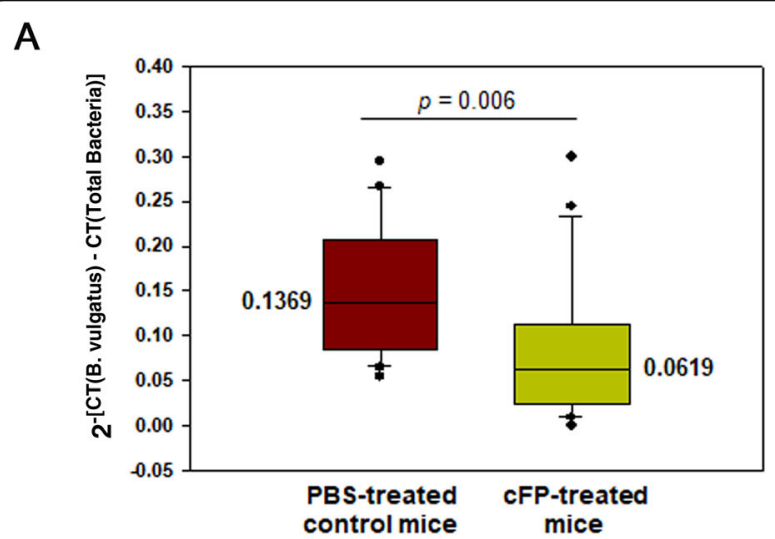

B

Inocular size of $V$. vulnificus (Cells)
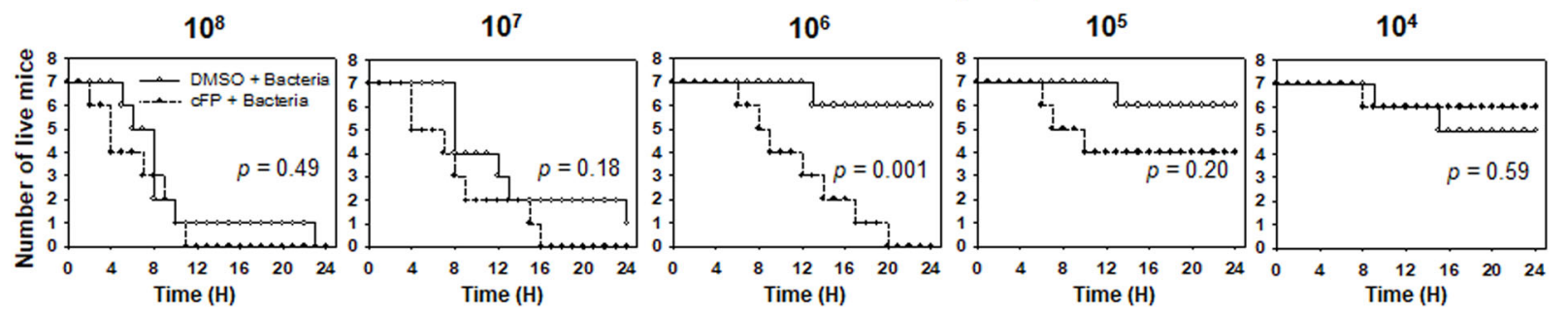

Fig. 9 In vivo effects of CFP in mice. A Effect of cFP on the abundance of B. vulgatus in fecal samples. The fecal samples were collected from four-week-old female mice orally injected with cFP or PBS ( $n=20$ mice per each set). The total DNA extracted from each fecal sample was subjected to q-PCR using a primer set specific to B. vulgatus $16 \mathrm{~S}$ rDNA and the universal primer set for eubacterial $16 \mathrm{~S}$ rDNA. The relative abundance of $B$. vulgatus $16 \mathrm{~S}$ rDNA was normalized with the abundance of the total bacterial $16 \mathrm{~S}$ rDNAs, and presented by the values of $2^{-[C T(B . v u l g a t u s)}-C T$ (Total Bacteria)] with their median numbers. Statistical analysis was performed using the Student's $t$-test and the resulting $P$-value was provided. B Effect of CFP on mouse lethality caused by $V$. vulnificus. Four-week-old female mice were orally injected with cFP as described above, then infected with various doses of $V$. vulnificus, ranging from $10^{4}$ to $10^{8}$ cells ( $n=7$ mice per each treatment) (open symbol). The same experiments were performed using the control mice, which had not been injected with cFP (closed symbol). The surviving mice were enumerated for $24 \mathrm{~h}$, and their numbers were plotted against incubation time. Statistical analyses were performed using the log-rank test and the resulting $P$-values were provided 
survival, regardless of the exogenous addition of cFP. However, the number of dead mice was higher in the cFP-treated sets of mice when they were preinjected with cFP then infected with $10^{5}-10^{7}$ cells of $V$. vulnificus. In cases of infection with $10^{6}$ cells of $V$. vulnificus, the difference in survival was significant, with a $P$-value of 0.001 (log-rank test).

\section{Discussion}

Cyclic dipeptides, formed by combining two amino acids through the reactions involving non-ribosomal peptide synthetases or cyclodipeptide synthases, are produced by a wide range of microorganisms [36]. Among them, pathogenic Vibrio species have been shown to produce cFP and secrete it in ambient environments at high concentrations [24]. The extracellular cFP serves as a signal molecule to regulate the expression of their virulence factors. For example, cFP induces the expression of ompU (encoding a major outer membrane protein) and $k a t G$ (encoding the hydroperoxidase I) via a regulatory pathway composed of ToxR and LeuO in V. vulnificus [37-39], but it downregulates the expression of ctx (encoding Cholera toxin) and tcpPH (encoding toxincoregulated pilus) via the ToxR-LeuO-AphA pathway in $V$. cholerae [40]. In addition to the role of cFP as a signal to bacteria themselves, cFP has the activities to their host cells by inhibiting the innate immune responses mediated by RIG-I and NF-kB $[27,41]$ and inducing the damage of mammalian DNA via increased ROS [42]. Therefore, the spectrum of roles of cFP in Vibrio pathogenicity has been broadened to be one of their virulence factors. Furthermore, the regulatory role of cFP at another level of $V$. vulnificus-host interactions was identified in this study. cFP was able to induce the cell death of $B$. vulgatus, a major constituent of the gut microbiota (Figs. 4 and 5). This finding is very interesting since a signal used by a pathogen to regulate its virulence factors is also utilized to change the gut environments to favor its pathogenicity by specifically transducing the signal to a group of gut commensals and removing these bacteria from the guts.

The survival of three strains of $B$. vulgatus in the presence of $V$. vulnificus and cFP was tested in this study: ATCC8482 from human feces; DSM28735 from a mouse caecum; and MGM001 isolated from a mouse feces (Figs. 2 and 4). A decrease in B. vulgatus CFUs in incubations with cFP was evidenced to be due to the actual death of bacterial cells, upon fluorescence microscopy observation of the B. vulgatus cells stained with the live/ dead-indicating dyes (Fig. 5A and B). cFP-mediated death of $B$. vulgatus was accompanied with alterations in membrane integrity, which was discernible in the images taken under the electron microscopes (Fig. 5C-F). Disruptive changes in their membranes were determined using a fluorescent dye DiSC3(5), which was incorporated into the bacterial membranes. Upon exposure to a membrane permeabilizing agent at its $\mathrm{EC}_{50}$ (e.g., 0.002\% Triton X-100), the released DiSC3(5) was monitored by fluorometry, showing that significantly more dyes were detected from the cFP-treated cells than the control (Fig. $7 \mathrm{~B})$. It suggests that $\mathrm{cFP}$ treatment made $B$. vulgatus membranes more susceptible to membrane permeabilizing stress. However, when cells were treated with other cyclic dipeptides consisting of hydrophobic amino acids (e.g., cPT and cPV) or a linear dipeptide of FP, the amounts of released DiSC3(5) upon exposure to $0.002 \%$ Triton X-100 were almost the same as those of the control (Additional file: Figure S2). Therefore, the effect of cFP on changing the membrane integrity is highly specific to B. vulgatus.

In addition to $B$. vulgatus, $P$. goldsteinii belonging to Bacteroidetes also showed the similar response to $\mathrm{V}$. vulnificus and cFP (Fig. 6). Microbiome composition data derived from two sets of experiments with the mice infected with $V$. vulnificus (Additional file: Table S1) showed a decrease in the abundance of $P$. goldsteinii in the $V$. vulnificus-fed mice, compared to the control PBSfed mice (Mann-Whitney $U$ test, $P=0.050$ ): from $1.81 \%$ $( \pm 0.96 \%)$ to $0.67 \%( \pm 0.18 \%)$ in experiment 1 ; and $0.91 \%$ $( \pm 0.41 \%)$ to $0.35 \%( \pm 0.003 \%)$ in experiment 2 . Furthermore, the fecal samples collected from mice orally injected with cFP, as shown in Fig. 9A, contained significantly less copies of $P$. goldsteinii-specific $16 \mathrm{~S}$ rRNA genes than the control mice $(P=0.038$, two-sided Student's $t$-test) (Additional file: Figure S3). In contrast, the abundance of $L$. reuteri-specific $16 \mathrm{~S}$ rRNA genes was not significantly altered in the control and cFP-fed mice ( $P=0.596$, two-sided Student's $t$-test). However, it is worth note that the abundance of $B$. caccae in mouse guts was not significantly affected by $V$. vulnificus infection (Mann-Whitney $U$ test, $P=0.221$ ) (Additional file: Table S1), and B. fragilis and B. ovatus exhibited high susceptibility to multiple dipeptides including cFP [43]. Therefore, it is speculated that cFP is a specific driver in the $V$. vulnificus-fed mice to reduce the abundance of some species of Bacteroides and Parabacteroides.

The specific interaction of cFP to B. vulgatus in inducing increased susceptibility to a membrane permeabilizing agent further suggests the presence of a specific sensor for cFP, which is able to induce cell death via membrane disruption. Previous studies have found that some bacterial proteins, e.g., RecA, CidA, and ObgE, play roles in regulating the permeabilization or depolarization of membranes [29-31]. Among them, ObgE of $B$. vulgatus responded to exogenously added cFP. The role of ObgE in cFP-mediated membrane disruption and subsequent cell death was not able to be confirmed with an obgE-deleted mutant of B. vulgatus, 
since the trials of $o b g E$ gene deletion have not been successful in diverse species of bacteria [33]. Increase in membrane disruption via ObgE was instead evidenced in the ObgE-overexpressing $B$. vulgatus, where the susceptibility degrees towards membrane-permeabilizing stress(es) were proportional to the cellular levels of ObgE (Fig. 8D and E). ObgE is a conserved GTPase among a wide-range of bacterial species, and it is reported to be essential for their viability by mediating the stringent response, ribosomal assembly, DNA replication and morphological differentiations including a sporulation process in spore-forming bacteria [31, 44, 45]. ObgE has been proposed to change the membrane potential of $E$. coli and $P$. aeruginosa by activating the expression of a toxin-antitoxin module of HokB and SokB under stringent conditions [31]. However, both $h o k B$ and $\operatorname{sok} B$ ORFs are not present in the genomes of B. vulgatus. Interestingly, a substitution of an amino acid residue in the $\mathrm{G}$ domain of $E$. coli's ObgE (ObgE*) resulted in the induction of programmed cell death via an unknown mechanism $[32,46]$. It is speculated that the ObgE of $B$. vulgatus may have activity similar to the ObgE*. Furthermore, since the B. vulgatus ObgE is specifically bound by cFP at a ratio of 1:1 (Fig. $8 \mathrm{C}$ ), formation of the cFPObgE complex increases this speculative activity inducing membrane disruption and subsequent cell death. In silico analysis of various ObgE homologs revealed that the ObgEs of B. vulgatus and P. goldsteinii have a conserved stretch of amino acids named by the DNA Pol Phi domain [47], which is overlapped with the fifth GTP-binding motif (G5) and the C-terminal domain (Additional file: Figure S4). In contrast, the ObgEs of other gut commensals including B. caccae and Lactobacillus spp. do not show the presence of this domain at their C-terminal regions. Future studies should identify the role of the conserved domain in the $B$. vulgatus ObgE in interacting with cFP and/or GTP, and the signal transducing mechanism underlying the membrane disruption via ObgE complexed with cFP.

Maintenance of normal microflora in GI tracts is important in the host response to pathogens [48]. Therefore, the conditions of an imbalance in the microbiota, such as reduced microbial diversity or fluctuated abundance of the obligate and facultative anaerobes in the gut microbiomes, resulted in high susceptibility to pathogenic colonization [48]. An obligate anaerobic Gram-negative bacterium, $B$. vulgatus, is a predominant microorganism in the mammalian GI tracts and the core gut commensal in healthy humans $[49,50]$. Although $B$. vulgatus shows the ability to efficiently metabolize some nutrients in the guts and plays roles in preventing inflammation and protecting the LPS-associating infections [51-53], it remains unclear why B. vulgatus is abundantly residing in the intestinal tracts and how it provides benefits to the host. In the present study, mice with decreased abundance of $B$. vulgatus in their guts due to pretreatment with cFP showed increased lethality when infected by some doses of $V$. vulnificus (Fig. 9A and B). These results lead us to speculate that this foodborne pathogen would increase its pathogenic potential by initially antagonizing the preexisting mouse gut commensals, which could strongly provide colonization barriers on the mucus layers [10]. Then, the pathogens could increase their accessibility to the gut epithelial cells and their success in causing fatal septicemia.

\section{Conclusions}

This study demonstrates a clear antagonistic effect of a foodborne pathogen, $V$. vulnificus, on a gut resident, $B$. vulgatus. This bacterial cell-to-cell interaction was specifically mediated by cFP and ObgE and caused B. vulgatus cells to be highly sensitive to the membranedisrupting stress(es). The cFP-mediated death of $B$. vulgatus was also observed in vivo; thus, a signal molecule of $V$. vulnificus, cFP, plays a role in enhancing its pathogenic potential in the host by modulating the abundance of the predominant species among gut commensals.

\section{Methods}

\section{Bacterial culture conditions}

All bacterial strains and plasmids used in this study are listed in the Additional file: Table S2. Vibrio strains were grown at $30 \sim 37{ }^{\circ} \mathrm{C}$ in LBS (Luria-Bertani [LB] medium containing $\mathrm{NaCl}$ at a final concentration of $2.5 \%[\mathrm{w} / \mathrm{v}]$ ) under aerobic conditions, unless otherwise mentioned. B. vulgatus and P. goldsteinii were grown in RCM (Reinforced Clostridial medium; BD Difco) in an anaerobic chamber (Whitley DG250 Anaerobic Workstation) adjusted to $37{ }^{\circ} \mathrm{C}$. Lactobacillus strains were grown at 37 ${ }^{\circ} \mathrm{C}$ in MRS (De Man, Rogosa and Sharpe; BD Difco) media under anaerobic conditions. For coculturing the cells of $V$. vulnificus and $B$. vulgatus on a single agar plate, each cell suspension was spotted on RCMS (RCM supplemented with $2.5 \%$ sodium chloride), and incubated in a $37{ }^{\circ} \mathrm{C}$ anaerobic chamber. E. coli used for plasmid DNA preparation and conjugal transfer were grown at $37{ }^{\circ} \mathrm{C}$ in LB medium supplemented with appropriate antibiotics. Antibiotics were used at the following concentrations: for E. coli, ampicillin at $100 \mu \mathrm{g} / \mathrm{ml}$ and chloramphenicol at $20 \mu \mathrm{g} / \mathrm{ml}$; for B. vulgatus, ampicillin at $10 \mu \mathrm{g} / \mathrm{ml}$; and for $V$. vulnificus, chloramphenicol at 2 $\mu \mathrm{g} / \mathrm{ml}$.

\section{Animal experiments}

Experiments were performed using 4- or 7-week-old female ICR mice (CrljOri:CD1[ICR], OrientBio, Korea). Mice were maintained at $23{ }^{\circ} \mathrm{C}$ and $50 \%$ humidity under the condition of a light/dark cycle of $12 / 12 \mathrm{~h}$, and had 
free access to water and food (LabDiet 5L79, OrientBio, Korea). After acclimation to these laboratory conditions for 2 days, mice were challenged to the specific treatments for each experiment. During the whole experiment procedures, mice received humane care in accordance with the institutional guidelines of Sogang University and the legal requirements (permit numbers, IACUCSGU2015_03 and IACUCSGU2019_01). All efforts were made to minimize animals suffering and to reduce the number of mice used.

\section{Fecal sample collection and microbiome analysis}

Seven-week-old female ICR mice were intraperitoneally injected with iron dextran $(30 \mu \mathrm{g}$ per gram of mouse weight) and intragastrically injected with $50 \mu \mathrm{l}$ of $8.5 \%$ $(\mathrm{w} / \mathrm{v})$ sodium bicarbonate. After $12 \mathrm{~h}$, each mouse was intragastrically infected with $2.0 \times 10^{9} \mathrm{~V}$. vulnificus cells suspended in phosphate buffered saline (PBS) using an oral gavage needle, then placed in a separate cage. As a control, mice were treated with $V$. vulnificus-free PBS (two mice per set of the infection experiment). Fecal samples were collected at every hour if they were present in the cages housing an individual mouse for 20 h. To compensate the probable variations among the batches of mice, two independent sets of infection experiments were performed, and the five and four fecal samples were retrieved from the dead and healthy mice, respectively.

The total DNAs in the samples were extracted using FastDNA $^{\circ}$ Spin Kit (MPbio), and the amounts of DNA were quantified by Epoch $^{\text {ntw }}$ Spectrophotometer (BioTek). DNA samples from experiments 1 and 2 were subjected to PCR to amplify the V1 to V3 regions of $16 \mathrm{~S}$ rDNA using the barcoded primers of 9F and 541R [54]. Products purified through the QIAquick PCR purification kit (Qiagen) were pooled together and the short non-target products were removed through the Ampure beads kit (Agencourt Bioscience). Quality control (QC) of the amplified DNA was assessed on a Bioanalyzer 2100 (Agilent) using a DNA 7500 Chip, and pyrosequencing was carried out with a GS Junior Sequencing system (Roche). Sequencing experiments were performed by ChunLab Inc (Korea) and the sequence data analyses were processed [55]. The obtained reads from the different samples were sorted by unique barcodes in each PCR product. The sequences corresponding to the barcode, linker, and primers were removed from the original sequencing reads. Any read containing multiple ambiguous nucleotides, low-quality score (average score < 25), or shorter than 300 bp were discarded. Potential chimera sequences, which were detected by the bellerophone method [56] were also removed. The taxonomic classification of each read derived from the experiments 1 and 2 was assigned against the EzTaxon-e database deposited in EzBioCloud [57], which contains 16S rRNA gene sequence of type strains that have valid published names and representative species-level phylotypes of either cultured or uncultured entries in the GenBank database with complete hierarchical taxonomic classification from the phylum to the species. Statistical analysis of the taxonomically classified sequencing data was processed using the EzBioClaud. Principal coordinates analysis (PCoA) of beta diversity metrics based on Jensen-Shannon distances was estimated and visualized using EzBioCloud. The difference of microbial communities among the fecal samples were calculated using permutational multivariate analysis of variance (PERMANOVA) [58].

\section{Isolation of mouse gut microorganisms}

To obtain pure cultures of bacteria in the mouse guts, the fecal samples collected from seven-week-old female ICR mice were resuspended in PBS. The resuspension was briefly centrifuged to eliminate fecal debris and the supernatants were retrieved. Diluted suspensions were spread onto GAM (Gifu Anaerobic medium; BD Difco), $\mathrm{RCM}$, or MRS agar plates and incubated at $37^{\circ} \mathrm{C}$ for 24 48 h under anaerobic conditions. Bacterial colonies were processed to amplify their $16 \mathrm{~S}$ rDNA fragments using the $27 \mathrm{~F}$ and $1492 \mathrm{R}$ primers and the purified PCR products were subjected to DNA sequencing analysis using the $785 \mathrm{~F}$ and $907 \mathrm{R}$ primers (Macrogen, Korea). Nine bacterial isolates showed more than $97 \%$ identity to the corresponding regions of $16 \mathrm{~S}$ rDNAs of B. vulgatus, P. goldsteinii, L. johnsonii, L. reuteri, L. murinus, or $L$ intestinalis, and were named by MGM001 to 009 (Additional file: Table S2). DNA sequences of $16 \mathrm{~S}$ rRNAs were deposited to the GenBank with accession numbers of MT764994 to MT765002.

\section{Survival tests of $B$. vulgatus}

Freshly grown cells of $B$. vulgatus were washed twice and resuspended in the M9-salt minimal medium [59] to contain cells at an $\mathrm{OD}_{595 \mathrm{~nm}}$ of 1.0. Then, the cell suspensions were added by various bacterial cells, their spent media (SM), or chemical compounds, and were incubated at $37^{\circ} \mathrm{C}$. All procedures were conducted in an anaerobic chamber. At the designated incubation time for each experiment, the mixtures were serially diluted with M9-salt minimal medium and the resultant aliquots were spread on the RCM agar plates. After $48 \mathrm{~h}$ of incubation in an anaerobic chamber, the viable $B$. vulgatus cells were counted. For coculture experiments, freshly grown Vibrio species (V. vulnificus, V. cholerae, and $V$. parahaemolyticus) and E. coli (a strain of S17-1 $\lambda$ pir) were harvested, washed twice, and resuspended in the M9-salt minimal medium to contain appropriate cell densities for each experiment. In case of coincubation with $V$. parahaemolyticus, which was able to grow on 
the RCM plate under anaerobic conditions, its CFUs were also enumerated by spreading the same samples on the TCBS (thiosulfate-citrate-bile salt-sucrose) agar plates under aerobic conditions and then subtracted from the total CFUs on the RCM plates incubated under anaerobic conditions. SM of $V$. vulnificus were prepared using $0.45 \mu \mathrm{m}$-pore-sized filter to sterilize the supernatants of the anaerobic culture in LBS. Solutions of organic acids (pyruvate, formate, lactate, and acetate [Sigma Aldrich]), cyclic dipeptides (cFP, cPV, and cPT [Bachem Inc.]), and a dipeptide (FP [Sigma Aldrich]) were prepared in the deionized water or DMSO.

\section{Microscopy observation}

B. vulgatus MGM001 cells treated with $\mathrm{cFP}(0,1,2$, and $4 \mathrm{mM}$ ) for $6 \mathrm{~h}$ were stained with a Live/Dead cell double staining kit (Sigma) and observed under a confocal laser scanning microscope (LSM700, Carl Zeiss). The viable cells were observed at an excitation wavelength of 488 $\mathrm{nm}$ and an emission wavelength of $515 \mathrm{~nm}$, and the dead cells were observed at an excitation wavelength of $535 \mathrm{~nm}$ and an emission wavelength of $617 \mathrm{~nm}$. The numbers of viable and dead cells, which were shown as green and red cells, respectively, were counted and their average numbers per microscope field were obtained through at least eight observations.

MGM001 cells treated with cFP ( 0 and $4 \mathrm{mM})$ for $6 \mathrm{~h}$ were processed for SEM analysis. Bacterial cells were fixed with $2 \%$ glutaraldehyde-paraformaldehyde in $0.1 \mathrm{M}$ phosphate buffer (PB, pH 7.4) for $24 \mathrm{~h}$ and then with $1 \%$ OsO4 dissolved in $0.1 \mathrm{M}$ PB for $1.5 \mathrm{~h}$. Fixed cells were dehydrated through an eight-stepped ascending gradual series of ethanol (from 50\% to 100\%), infiltrated with isoamyl acetate, and placed in the Critical Point Dryer (Leica EM CPD300). The resultant samples were coated with $5 \mathrm{~nm}$-thick $\mathrm{Pt}$ by an Ion Coater (Leica EM ACE600) and examined under Merlin ${ }^{\text {TM }}$ FE-SEM (Carl Zeiss) operating at $2 \mathrm{kV}$.

B. vulgatus (MGM001, ATCC8482, and DSM28735) and P. goldsteinii (MGM002) exposed to cFP (0 and 4 $\mathrm{mM}$ ) for $6 \mathrm{~h}$ were processed for TEM analysis. The cells fixed by treating with $2 \%$ glutaraldehydeparaformaldehyde (for $12 \mathrm{~h}$ ) and $1 \% \mathrm{OsO} 4$ (for $2 \mathrm{~h}$ ) were dehydrated as described above, and infiltrated with propylene oxide. Then, samples were embedded using the Poly/Bed 812 kit (Polysciences) and treated at $65{ }^{\circ} \mathrm{C}$ for $24 \mathrm{~h}$ in an electron microscope oven (TD-700, Dosaka). Polymerized samples were sectioned (200-250 nm) using ultramicrotome, then further thin-sectioned (70 $\mathrm{nm}$ ) using Leica EM UC-7 (Leica Microsystems) and a diamond knife (Diatome). The sections were doublestained with $6 \%$ uranyl acetate and lead citrate, transferred onto the copper-nickel grids (Electron
Microscopy Science), and examined under JEM-1011 TEM (JEOL).

\section{Membrane permeability assay}

The effect of cFP on bacterial membrane permeability was determined using a membrane potential-sensitive fluorescent dye, DiSC3(5) (Sigma). Freshly grown $B$. vulgatus cells were washed twice and resuspended in the M9-salt minimal medium to contain cells at an $\mathrm{OD}_{595} \mathrm{~nm}$ of 1.0. Four millimolar cFPs dissolved in DMSO were added to the cell suspension. The same volume of DMSO was added as a control. At $6 \mathrm{~h}$ of exposure to cFP or DMSO, cells were washed twice with $5 \mathrm{mM}$ HEPES buffer ( $\mathrm{pH}$ 7.4) and then treated for $1 \mathrm{~h}$ with $0.4 \mu \mathrm{M}$ of DiSC3(5) dissolved in $5 \mathrm{mM}$ HEPES including $100 \mathrm{mM} \mathrm{KCl}$. After unincorporated dyes were discarded, the cells were resuspended in the same volume of $5 \mathrm{mM}$ HEPES. Aliquots $(100 \mu \mathrm{l})$ of the dye-associated cells were placed in 96-well black polystyrene microplates (SPL life science). RFUs were measured in a fluorometer (EnSpire Multimode Plate Reader, PerkinElmer), for which the temperature was set at $30{ }^{\circ} \mathrm{C}$ and wavelengths of 622 and $670 \mathrm{~nm}$, for excitation and emission, respectively. At $0.5 \mathrm{~h}$ in a fluorometer, Triton X-100 $(0.002 \%$ or $0.1 \%)$ was added to each well and the RFUs were continuously measured for another $0.5 \mathrm{~h}$. The released fluorescence from the Triton X-100-treated B. vulgatus cells was obtained by subtracting the values of basal RFU (averaged RFUs for 10 min before treatment of Triton X100) from the maximal RFU (averaged RFUs for 10 min after treatment of Triton X-100).

\section{Construction of $B$. vulgatus expressing obgE in response to arabinose}

A 1185-bp DNA fragment containing the $o b g E$ gene of $B$. vulgatus, which was amplified using the primers of ObgE_pBAD-F and ObgE_pBAD-R (Additional file: Table S3), was digested with NcoI and $\mathrm{KpnI}$ and ligated into a vector plasmid $\mathrm{pBAD} / \mathrm{Myc}-\mathrm{His} \mathrm{B}$. The resultant

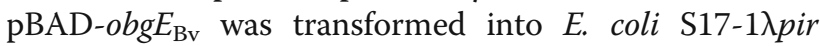
then transferred to $B$. vulgatus MGM001, which is naturally sensitive to ampicillin, via conjugation between two species of bacteria. B. vulgatus harboring pBAD$o b g E_{\mathrm{Bv}}$ was selected by spreading aliquots of the conjugate mixture on the RCM agar plate supplemented with $10 \mu \mathrm{g} / \mathrm{ml}$ ampicillin and incubating in an anaerobic chamber.

\section{Western blotting analysis using anti-ObgE and anti-RecA polyclonal antibodies}

Two oligonucleotides, Bv_obgE-over $\mathrm{F}$ and Bv_obgEover R (Additional file: Table S3), were used to amplify a 1185 bp DNA fragment containing obgE ORF from the 
genomic DNA of B. vulgatus MGM001. Amplified DNA fragments were digested with BamHI and SalI, and cloned into pET28b to generate pET28b-obgE. In the same way, DNA fragments containing recA ORF (1064 bp) amplified using Bv_recA-over $\mathrm{F}$ and $\mathrm{Bv} \_$recA-over $\mathrm{R}$ (Additional file: Table S3) were cloned into pET28b to generate pET28b-recA. Each recombinant protein was overexpressed in E. coli BL21 by adding $1 \mathrm{mM}$ of IPTG and purified using a Ni-NTA affinity column, as directed by the manufacturer (Qiagen). The purified recombinant proteins were used to generate polyclonal antibodies by the three immunizations of ICR mice (CrljOri: CD1[ICR] $) \quad(100 \mu \mathrm{g}$ of recombinant proteins per immunization) at 3-week intervals.

To prepare the total cell lysates of $B$. vulgatus, cells were resuspended in Tris-buffered saline with Tween 20 (TBST; $150 \mathrm{mM} \mathrm{NaCl}, 50 \mathrm{mM}$ Tris- $\mathrm{HCl}$, and $0.1 \%$ Tween 20) and lysed by sonication. Then, $20 \mu \mathrm{g}$ of each cell lysate was loaded onto a 12\% SDS-PAGE, run for 1 $\mathrm{h}$ at $120 \mathrm{~V}$, and transferred to Hybond $\mathrm{P}$ membrane (Amersham). Membranes were blocked with 5\% skim milk in TBST for $30 \mathrm{~min}$ and incubated overnight at $4^{\circ} \mathrm{C}$ with each polyclonal antibody (1:5000, [vol/vol]), followed by alkaline phosphatase-conjugated rabbit antimouse IgG (1:5000, [vol/vol]). Immunoreactive bands were visualized using the NBT-BCIP system (Promega).

\section{Isothermal titration calorimetry}

Binding characteristics of rObgE to cFP were analyzed using the MicroCal iTC200 system (Malvern Panalytical) with a reference power of $10 \mu \mathrm{cal} / \mathrm{s}$. The thermodynamic parameters upon titration of $\mathrm{rObgE}(40 \mu \mathrm{M}$, nucleotidefree) with a solution of $400 \mu \mathrm{M}$ cFP were measured at $25{ }^{\circ} \mathrm{C}$ in a buffer consisting of $20 \mathrm{mM}$ HEPES (pH 7.5), $150 \mathrm{mM} \mathrm{NaCl}, 5 \mathrm{mM} \mathrm{MgCl}_{2}$, and $1 \mathrm{mM} \beta$ mercaptoethanol. The nucleotide-free $\mathrm{rObgE}$ was prepared by treating with calf intestine alkaline phosphatase (Promega) and passing a gel filtration AKTA-FPLC system (Superdex 200, GE Healthcare) at a flow rate of 0.3 $\mathrm{ml} / \mathrm{min}$ in a buffer containing $20 \mathrm{mM}$ HEPES (pH 7.5), $150 \mathrm{mM} \mathrm{NaCl}$, and $5 \mathrm{mM} \mathrm{MgCl}_{2}$ as previously described [60]. rObgE in the eluted fractions $(1 \mathrm{ml})$ was concentrated using Amicon ${ }^{\circ}$ Ultra-15 10K (Millipore) and its buffer was exchanged with that used for an ITC assay. To obtain the equilibrium dissociation constant $\left(\mathrm{K}_{\mathrm{D}}\right)$ and binding stoichiometry $(N)$, the data were fitted to a single binding site model using the standard Marquardt non-linear regression method as provided from the MicroCal ITC-Origin Analysis (Malvern Panalytical).

\section{Quantitative PCR}

Fecal samples were collected from the mice fed with PBS or cFP for 6 and $24 \mathrm{~h}$, and their bacterial DNAs were extracted using ZymoBIOMICS ${ }^{\mathrm{TM}}$ DNA miniprep kit (ZYMO research). Using $2.5 \mathrm{ng}$ of DNA in each sample, qPCR was run with the primer set specific to $16 \mathrm{~S}$ rDNA of B. vulgatus (Bv-F and Bv-R; 34) and the universal primer set of 785F and 907R [35] using a LightCycler 480 II (Roche Life Science). Threshold cycle (CT) values representing the relative quantities of the $B$. vulgatusspecific $16 \mathrm{~S} \mathrm{rDNA}$ and the total bacterial $16 \mathrm{~S}$ rDNAs in each sample were obtained and the values of $2^{-[\mathrm{CT}(\text { B.vulgatus })}$ - CT(Total Bacteria)] were calculated by the $2^{-\Delta \Delta C T}$ method [61]. The primers used in this assay are listed in the Additional file: Table S3.

\section{Mouse lethality assay}

To examine the mortality of the mice infected with $V$. vulnificus in the presence of cFP, four-week-old female ICR mice (CrljOri:CD1[ICR]), which have been starved for 12 $\mathrm{h}$, were intragastrically treated with $\mathrm{cFP}(110 \mu \mathrm{g} \mathrm{cFP}$ per gram of mouse) for $12 \mathrm{~h}$ prior to $V$. vulnificus infection. Before bacterial infection, each mouse was intraperitoneally injected with iron dextran $(30 \mu \mathrm{g}$ per gram of mice weight) and intragastrically injected with $8.5 \%$ [w/vol.] sodium bicarbonate $(50 \mu \mathrm{l})$. Various concentrations of freshly grown $V$. vulnificus were resuspended in PBS and injected intragastrically into seven mice per set. Since cFP was dissolved in PBS mixed with 1\% DMSO, the same volume of buffer was injected intragastrically as a control. The number of dead mice was counted for $24 \mathrm{~h}$.

\section{Statistical analyses}

Results were expressed as the mean \pm standard deviation $(\mathrm{SD})$ or median $\pm \mathrm{SD}$ in the three independent experiments. Statistical analysis was performed using Student's $t$-test (SYSTAT program, SigmaPlot version 9, Systat Software Inc.). A log-rank test (http://bioinf.wehi.edu.au/ software/russell/logrank/) was performed to estimate statistical significance of the mouse mortality results. Differences were considered significant if $P$-values were $\leq 0.01$. $P$-values were presented in the corresponding figures, or their significance was indicated by * or **, when $0.001<P \leq 0.01$ or $P<0.001$, respectively.

\section{Abbreviations \\ CFP: Cyclo-(phenylalanine-proline); CFU: Colony-forming unit; CPT: Cyclo- (proline-threonine); cPV: Cyclo-(proline-valine); DiSC3(5): 3,3'- \\ Dipropylthiadicarbocyanine iodide; ITC: Isothermal titration calorimetry; RFU: Relative fluorescence unit; SM: Spent medium}

\section{Supplementary Information}

The online version contains supplementary material available at https://doi. org/10.1186/s40168-021-01095-w.

Additional file 1.

Acknowledgements

The authors thank Prof. S-J Park and Dr. J Kim (Yonsei University College of Medicine) for SEM and TEM analysis. 


\section{Authors' contributions}

J.-A.K., B.-R.J., and K.-H.L. designed and coordinated the study.; J.-A.K., B.-R.J., Y.-R.K., and Y.-C.J. performed experiments and acquired the data.; J.-A.K., B.R.J., Y.-C.J., K.-S.K., and K.-H.L. analyzed the data; J.-A.K. B.-R.J. and K.-H.L. wrote the paper with input from Y.-C.J. and K.-S.K.; K.-H.L. supervised the work. All the authors participated in discussions of the results and reviewed the final draft. The authors read and approved the final manuscript.

\section{Funding}

This work was supported by grants from the National Research Foundation, Republic of Korea (NRF-2018R1A5A1025077 [Microbial Survival Systems Research Center] and NRF-2021R1A2B5B02002477)

\section{Availability of data and materials}

Amplicon data for the phylum Bacteroidetes are in the Additional file: Table S1; information for the bacterial strains, plasmids, and oligonucleotide primers are listed in the Additional file: Tables S2 and S3; the $16 \mathrm{~S}$ rRNA sequences for the MGM isolates were deposited to the GenBank with accession numbers of MT764994 to MT765002.

\section{Declarations}

\section{Ethics approval and consent to participate}

For the experiments using mice, all the animals received humane care in accordance with the institutional guidelines of Sogang University and the legal requirements (IACUCSGU2015_03 and IACUCSGU2019_01).

\section{Consent for publication}

Not applicable.

\section{Competing interests}

The authors declare no conflict of interests.

Received: 27 April 2021 Accepted: 12 May 2021

Published online: 20 July 2021

\section{References}

1. Flint A, Butcher J, Stintzi A. Stress responses, adaptation, and virulence of bacterial pathogens during host gastrointestinal colonization. Microbiol Spectr. 2016;4. https://doi.org/10.1128/microbiolspec.VMBF-0007-2015.

2. Hillman ET, Lu H, Yao T, Nakatsu CH. Microbial ecology along the gastrointestinal tract. Microbes Environ. 2017;32:300-13. https://doi.org/10.12 64/jsme2.ME17017.

3. Takiishi T, Fenero CIM, Câmara NOS. Intestinal barrier and gut microbiota: shaping our immune responses throughout life. Tissue Barriers. 2017;5: e1373208. https://doi.org/10.1080/21688370.2017.1373208.

4. Horn N, Bhunia AK. Food-associated stress primes foodborne pathogens for the gastrointestinal phase of infection. Front Microbiol. 2018;9:1962. https:// doi.org/10.3389/fmicb.2018.01962.

5. Ribet D, Cossart P. How bacterial pathogens colonize their hosts and invade deeper tissues. Microbes Infect. 2015;17:173-83. https://doi.org/10.1016/j. micinf.2015.01.004

6. Peterson KM, Gellings PS. Multiple intraintestinal signals coordinate the regulation of Vibrio cholerae virulence determinants. Pathog Dis. 2018;76. https://doi.org/10.1093/femspd/ftx126.

7. Phillips KE, Satchell KJ. Vibrio vulnificus: From oyster colonist to human pathogen. PLoS Pathog. 2017;13:e1006053. https://doi.org/10.1371/journal. ppat.1006053

8. Jones MK, Oliver JD. Vibrio vulnificus: Disease and pathogenesis. Infect Immun. 2009;77:1723-33. https://doi.org/10.1128/IAl.01046-08.

9. Heng SP, Letchumanan $V$, Deng $C Y$, et al. Vibrio vulnificus: an environmental and clinical burden. Front Microbiol. 2017;8:997. https://doi.org/10.3389/ fmicb.2017.00997.

10. Guarner F, Malagelada JR. Gut flora in health and disease. Lancet. 2003;361: 512-9. https://doi.org/10.1016/S0140-6736(03)12489-0.

11. D'Argenio $V$, Salvatore $F$. The role of the gut microbiome in the healthy adult status. Clin Chim Acta. 2015;451:97-102. https://doi.org/10.1016/j.cca.2 015.01.003.

12. Martens EC, Neumann M, Desai MS. Interactions of commensal and pathogenic microorganisms with the intestinal mucosal barrier. Nat Rev Microbiol. 2018;16:457-70. https://doi.org/10.1038/s41579-018-0036-x.
13. Sassone-Corsi M, Raffatellu M. No vacancy: how beneficial microbes cooperate with immunity to provide colonization resistance to pathogens. J Immunol. 2015;194:4081-7. https://doi.org/10.4049/jimmunol.1403169.

14. van der Waaij $\mathrm{D}$. The digestive tract in immunocompromised patients: importance of maintaining its resistance to colonization, especially in hospital in-patients and those taking antibiotics. Antonie Van Leeuwenhoek. 1984;50:745-61. https://doi.org/10.1007/BF02386238.

15. Sekirov I, Russell SL, Antunes LC, Finlay BB. Gut microbiota in health and disease. Physiol Rev. 2010;90:859-904. https://doi.org/10.1152/physrev.0004 5.2009 .

16. Kim S, Covington A, Pamer EG. The intestinal microbiota: antibiotics, colonization resistance, and enteric pathogens. Immunol Rev. 2017;279:90105. https://doi.org/10.1111/imr.12563.

17. Ferreira RB, Gill N, Willing BP, et al. The intestinal microbiota plays a role in Salmonella-induced colitis independent of pathogen colonization. PLoS One. 2011;6:e20338. https://doi.org/10.1371/journal.pone.0020338.

18. Zachar Z, Savage DC. Microbial interference and colonization of the murine gastrointestinal tract by Listeria monocytogenes. Infect Immun. 1979;23:16874. https://doi.org/10.1128/IAl.23.1.168-174.1979.

19. Chassaing B, Koren O, Carvalho FA, Ley RE, Gewirtz AT. AlEC pathobiont instigates chronic colitis in susceptible hosts by altering microbiota composition. Gut. 2014;63:1069-80. https://doi.org/10.1136/gutjnl-2013-304 909.

20. You JS, Yong JH, Kim GH, et al. Commensal-derived metabolites govern Vibrio cholerae pathogenesis in host intestine. Microbiome. 2019;7:132 https://doi.org/10.1186/s40168-019-0746-y.

21. Chen C, Yang X, Shen X. Confirmed and potential roles of bacterial T6SSs in the intestinal ecosystem. Front Microbiol. 2019;10:1484. https://doi.org/10.33 89/fmicb.2019.01484.

22. Rolhion N, Chassaing B. When pathogenic bacteria meet the intestinal microbiota. Philos Trans R Soc Lond B Biol Sci. 2016;371:20150504. https:// doi.org/10.1098/rstb.2015.0504.

23. García-López M, Meier-Kolthoff JP, Tindall BJ, et al. Analysis of 1000 typestrain genomes improves taxonomic classification of Bacteroidetes. Front Microbiol. 2019;10:2083. https://doi.org/10.3389/fmicb.2019.02083.

24. Kim K, Kim NJ, Kim SY, Kim IH, Kim KS, Lee GR. Cyclo(Phe-Pro) produced by the human pathogen Vibrio vulnificus inhibits host innate immune responses through the NF-kB pathway. Infect Immun. 2015:83:1150-61. https://doi.org/10.1128/IAl.02878-14.

25. Ma LS, Narberhaus F, Lai EM. I cmF family protein TssM exhibits ATPase activity and energizes Type VI secretion. J Biol Chem. 2012;287:15610-21. https://doi.org/10.1074/jbc.M111.301630.

26. Lee $\mathrm{KJ}$, Jeong $\mathrm{CS}, \mathrm{An} \mathrm{YJ}$, et al. FrsA functions as a cofactor-independent decarboxylase to control metabolic flux. Nat Chem Biol. 2011;7:434-6. https://doi.org/10.1038/nchembio.589.

27. Park DK, Lee KE, Baek CH, et al. Cyclo(Phe-Pro) modulates the expression of ompU in Vibrio spp. J Bacteriol. 2006;188:2214-21. https://doi.org/10.1128/ JB.188.6.2214-2221.2006

28. Nüsslein K, Arnt L, Rennie J, Owens C, Tew GN. Broad-spectrum antibacterial activity by a novel abiogenic peptide mimic. Microbiology. 2006;152:1913-8. https://doi.org/10.1099/mic.0.28812-0.

29. Erental A, Sharon I, Engelberg-Kulka H. Two programmed cell death systems in Escherichia coli: An apoptotic-like death is inhibited by the mazEFmediated death pathway. PLoS Biol. 2012;10:e1001281. https://doi.org/10.13 71/journal.pbio.1001281

30. Ranjit DK, Endres JL, Bayles KW. Staphylococcus aureus CidA and LrgA proteins exhibit holin-like properties. J Bacteriol. 2011;193:2468-76. https:// doi.org/10.1128/JB.01545-10.

31. Verstraeten $\mathrm{N}$, Knapen WJ, Kint Cl, et al. Obg and membrane depolarization are part of a microbial bet-hedging strategy that leads to antibiotic tolerance. Mol Cell. 2015;59:9-21. https://doi.org/10.1016/j.molcel.2015.05. 011.

32. Dewachter $L$, Verstraeten $N$, Monteyne $D$, et al. A single-amino-acid substitution in Obg activates a new programmed cell death pathway in Escherichia coli. mBio. 2015;6:e01935-15. https://doi.org/10.1128/mBio.0193 5-15.

33. Verstraeten N, Fauvart M, Versées W, Michiels J. The universally conserved prokaryotic GTPases. Microbiol Mol Biol Rev. 2011;75:507-42. https://doi. org/10.1128/MMBR.00009-11.

34. Wang RF, Cao WW, Cerniglia CE. PCR detection and quantitation of predominant anaerobic bacteria in human and animal fecal samples. App 
Environ Microbiol. 1996;62:1242-7. https://doi.org/10.1128/AEM. 62.4.1242-1247.1996.

35. Ziesemer KA, Mann AE, Sankaranarayanan $K$, et al. Intrinsic challenges in ancient microbiome reconstruction using $16 \mathrm{~S}$ rRNA gene amplification. Sc Rep. 2015;5:16498. https://doi.org/10.1038/srep16498.

36. Prasad C. Bioactive cyclic dipeptides. Peptides. 1995;16:151-64. https://doi. org/10.1016/0196-9781(94)00017-z.

37. Kim IH, Kim SY, Park NY, et al. Cyclo-(L-Phe-L-Pro), a quorum-sensing signal of Vibrio vulnificus, induces expression of hydroperoxidase through a ToxRLeuO-HU-RpoS signaling pathway to confer resistance against oxidative stress. Infect Immun. 2018;86:e00932-17. https://doi.org/10.1128/IAl.00932-1 7.

38. Park NY, Kim IH, Wen Y, et al. Multi-factor regulation of the master modulator LeuO for the cyclic-(Phe-Pro) signaling pathway in Vibrio vulnificus. Sci Rep. 2019;9:20135. https://doi.org/10.1038/s41598-019-56855-4.

39. Park NY, Lee KW, Kim KS. H-NS silences gene expression of LeuO, the master regulator of the cyclic(Phe-Pro)-dependent signal pathway, in Vibrio vulnificus. J Microbiol Biotechnol. 2020;30:830-8. https://doi.org/10.4014/ jmb.2001.01021.

40. Bina XR, Taylor DL, Vikram A, Ante VM, Bina JE. Vibrio cholerae ToxR downregulates virulence factor production in response to cyclo(Phe-Pro). mBio. 2013;4:e00366-13. https://doi.org/10.1128/mBio.00366-13.

41. Lee W, Lee $\mathrm{SH}$, Kim M, et al. Vibrio vulnificus quorum-sensing molecule cyclo(Phe-Pro) inhibits RIG-I-mediated antiviral innate immunity. Nat Commun. 2018;9:1606. https://doi.org/10.1038/s41467-018-04075-1.

42. Lee K, Jeong JE, Kim IH, Kim KS, Ju BG. Cyclo(phenylalanine-proline) induces DNA damage in mammalian cells via reactive oxygen species. J Cell Mol Med. 2015;19:2851-64. https://doi.org/10.1111/jcmm.12678.

43. Rhee HK. In vitro activity of cyclic dipeptides against gram-positive and gram-negative anaerobic bacteria and radioprotective effect on lung cells. J. Microbiol Biotechnol. 2006;16:158-62.

44. Kint C, Verstraeten N, Hofkens J, Fauvart M, Michiels J. Bacterial Obg proteins: GTPases at the nexus of protein and DNA synthesis. Crit Rev Microbiol. 2014;40:207-24. https://doi.org/10.3109/1040841X.2013.776510.

45. Dewachter L, Verstraeten N, Fauvart M, Michiels J. An integrative view of cell cycle control in Escherichia coli. FEMS Microbiol Rev. 2018;42:116-36. https:// doi.org/10.1093/femsre/fuy005.

46. Dewachter L, Herpels P, Verstraeten N, Fauvart M, Michiels J. Reactive oxygen species do not contribute to ObgE*-mediated programmed cell death. Sci Rep. 2016;6:33723. https://doi.org/10.1038/srep33723.

47. Shimizu K, Kawasaki Y, Hiraga S, Tawaramoto M, Nakashima N, Sugino A. The fifth essential DNA polymerase phi in Saccharomyces cerevisiae is localized to the nucleolus and plays an important role in synthesis of rRNA. Proc Natl Acad Sci U S A. 2002;99:9133-8. https://doi.org/10.1073/pnas.1422 77999.

48. Bäumler AJ, Sperandio V. Interactions between the microbiota and pathogenic bacteria in the gut. Nature. 2016;535:85-93. https://doi.org/10.1 038/nature18849.

49. Qin J, Li R, Raes J, et al. A human gut microbial gene catalogue established by metagenomic sequencing. Nature. 2010;464:59-65. https://doi.org/10.103 8/nature08821.

50. Szöke I, Pascu C, Nagy E, Ljung A, Wadström T. Binding of extracellular matrix proteins to the surface of Bacteroides spp. Anaerobe. 1997;3:91-5. https://doi.org/10.1006/anae.1997.0079.

51. Waidmann M, Bechtold O, Frick JS, et al. Bacteroides vulgatus protects against Escherichia coli-induced colitis in gnotobiotic interleukin-2-deficient mice. Gastroenterology. 2003;125:162-77. https://doi.org/10.1016/s00165085(03)00672-3.

52. Maerz JK, Steimle A, Lange A, Bender A, Fehrenbacher B, Frick JS. Outer membrane vesicles blebbing contributes to $B$. vulgatus mpk-mediated immune response silencing. Gut Microbes. 2018;9:1-12. https://doi.org/10.1 080/19490976.2017.1344810

53. Yoshida N, Emoto T, Yamashita T, et al. Bacteroides vulgatus and Bacteroides dorei reduce gut microbial lipopolysaccharide production and inhibit atherosclerosis. Circulation. 2018;138:2486-98. https://doi.org/10.1161/ CIRCULATIONAHA.118.033714.

54. Sohn SH, Kim N, Jo HJ, et al. Analysis of gastric body microbiota by pyrosequencing: possible role of bacteria other than Helicobacter pylori in the gastric carcinogenesis. J Cancer Prev. 2017;22(2):115-25. https://doi. org/10.15430/JCP.2017.22.2.115
55. Chun J, Kim KY, Lee JH, Choi Y. The analysis of oral microbial communities of wild-type and toll-like receptor 2-deficient mice using a 454 GS FLX titanium pyrosequencing. BMC Microbiol. 2010;10:101. https://doi.org/10.11 86/1471-2180-10-101.

56. Huber T, Faulker G, Hugenholtz P. Bellerophon: a program to detect chimeric sequences in multiple sequence alignments. Bioinformatics. 2004; 20:2317-9. https://doi.org/10.1093/bioinformatics/bth226.

57. Yoon SH, Ha SM, Kwon S, et al. Introducing EzBioCloud: A taxonomically united database of 165 rRNA gene sequences and whole-genome assemblies. Int J Syst Evol Microbiol. 2017;67:1613-7. https://doi.org/10.1 099/ijsem.0.001755.

58. Anderson MJ. Permutational multivariate analysis of variance (PERMANOVA). Hoboken: Wiley StatsRef: Statistics Reference Online; 2017. p. 1-15. https:// doi.org/10.1002/9781118445112.stat07841.

59. Sambrook J, Russell D. Molecular cloning: a laboratory manual. 3rd ed. New York: Cold Spring Harbor Laboratory Press; 2001.

60. Dewachter L, Deckers B, Martin E, et al. GTP binding is necessary for the activation of a toxic mutant isoform of the essential GTPase ObgE. Int J Mol Sci. 2019;21:16. https://doi.org/10.3390/ijms21010016.

61. Livak KJ, Schmittgen TD. Analysis of relative gene expression data using real-time quantitative PCR and the $2^{-\Delta \Delta C T}$ method. Methods. 2001;25:402-8. https://doi.org/10.1006/meth.2001.1262.

\section{Publisher's Note}

Springer Nature remains neutral with regard to jurisdictional claims in published maps and institutional affiliations.
Ready to submit your research? Choose BMC and benefit from:

- fast, convenient online submission

- thorough peer review by experienced researchers in your field

- rapid publication on acceptance

- support for research data, including large and complex data types

- gold Open Access which fosters wider collaboration and increased citations

- maximum visibility for your research: over $100 \mathrm{M}$ website views per year

At BMC, research is always in progress.

Learn more biomedcentral.com/submissions 